\title{
KETOGENIC DIETS: OPPORTUNITIES AND LIMITATIONS IN PRACTICAL APPLICATION
} (LITERATURE REVIEW)

Article history:

Submitted 19 June 2019

Accepted 31 July 2019

\section{Georg Tyminski}

European Scientific Society, Hanover, Germany

ewg2002@gmail.com

ABSTRACT — During almost 100 years ketogenic diets (KD) were used for treatment of epilepsy and certain metabolic deficiencies (GLUT1 deficiency and Pyruvate dehydrogenase (PDHD). It has been widely suggested that $\mathrm{KD}$ and their preparations might be used to treat obesity, cancer and to prevent neurodegenerative diseases (dementia, Alzheimer's, etc.), diabetes and cardiovascular diseases and even aging.

The literature review provides evidence for KD efficiency in reduction of epileptic seizures in children and adults. However, the majority of research and the professional communities of dietologists, such as German Nutrition Society and German Cancer Soceity warn of adverse health effects of KD when used for other conditions. Additional studies are therefore required.

KEY W ORDS - classic ketogenic diet, ketogenic diet, modified Atkins diet, Low Glycemic Index-Treatment, intermittent fasting, Alternate - day fasting, High Fat Low Carbohydrate, time-restricted feeding, overnight-fasting, medium chain fatty acids, long chain triglycerides, medium chain triglycerides, fatty acids, carbohydrates, proteins, amino acid, ketones, $\beta$-hydroxybutyrate, adenosine triphosphate, ketogenic metabolic therapy, obesity, epilepsy, glucose transporter type 1 deficiency syndrome, Pyruvatdehydrogenase Deficiency, Multiple Acyl-CoADehydrogenase Deficiency, hyperinsulinism, type 2 diabetes.

\section{Abbreviations:}
FA: fatty acids
CH: carbohydrates
AA: amino acid
BHB: $\beta$-hydroxybutyrate
AcAc: acetoacetate
MCT: medium chain triglyc- erides
MCFA: medium chain fatty
acids
LCT: long chain triglycerides
LCFA: long chain fatty acids
ATP: adenosine triphosphate
Glut1-DS: glucose transporter
type 1
MADD: Multiple Acyl-CoA-
Dehydrogenase Deficiency

\section{KETOGENIC DIETS}

The popularity of the classic ketogenic diet (CKD), developed for the treatment of childhood epilepsy in the 1920s and widely used in the decade to follow, has declined with the confirmation of the effectiveness of anti-convulsants.

In the mid-1990s, the Hollywood producer Jim Abraham, whose son had successfully dealt with his seizures by means of the classic ketogenic diet, established a foundation to attract attention and revive scientific interest in the diet.

Experts believe that a ketogenic diet works in half of the cases, and in one third of cases it produces very good results (1). In 2008, a randomised clinical trial found an advantage in children with difficult cases of epilepsy who adhere to a classic ketogenic diet (CKD). An improvement in treatment over a period of 6-24 months was observed in over $90 \%$ of cases $(1,57)$.

A "classic" ketogenic diet (CKD) is a strictly balanced diet consisting of a fixed weight ratio (content) between fats, proteins and carbohydrates (standard 4:1, i.e. 4 grams of fat to 1 gram of protein and carbohydrates). For children under 2 years of age, this ratio is $3: 1$, otherwise the age requirement for protein is not guaranteed (1).

The fats used in the classic ketogenic diet (CKD) are mainly triglycerides with long-chain fatty acids (LCT). There are also options for the use of medium chain triglycerides (MCTs).

The protein content of the ketogenic diet is calculated using DGE recommendations for each age group (2).

In general, the amount of fat, protein and carbohydrates is calculated proportionally according to a fixed weight ratio. This fixed ratio should be maintained for each meal [3].

The KD is based on the formation of ketone bodies from acetyl-CoA, which is formed by the breakdown of fatty acids. In this context, ketone bodies are the water-soluble molecules (acetoacetate(AcAc), beta-hydroxybutyrate $(\beta \mathrm{HB})$, and the spontaneous breakdown product of acetoacetate, acetone) $(4,5)$.

The path to the formation of ketone bodies (ketogenesis) occurs in the mitochondria of liver cells. 
In this catabolic pathway, fatty acids are converted into acetoacetate at the end of $\beta$-oxidation through acetyl-KoA.

There are three ways to trigger ketosis - meaning an increase in the level of ketone bodies in the blood. These are fasting (hunger), exercises, or a very highfat diet with simultaneous reduction of carbohydrate intake $(6,7,8)$. In all three cases, the glucose deficit and the stimulation of lipolysis trigger the production of an alternative source of energy, which is particularly important for the brain. This alternative source of energy is the ketone bodies, and especially $\beta \mathrm{HB}$, which is the most abundant among them (9).

In order to significantly increase the level of ketone bodies in the blood (> $2 \mathrm{mmol} / \mathrm{L}$ ), $60-90 \%$ of daily energy intake (E\%; Low Glycemic Index Treatment (LGIT) vs. classic kD 4:1) need to come from fat (10). Generally, it is assumed that in adults, a carbohydrate $(\mathrm{CH})$ intake of over $50 \mathrm{~g}$ per day will not produce ketosis or will only do so to a very limited extent (11). The fact that this diet is so different from a normal balanced diet leads to problems with compliance, which in turn leads to treatment discontinuation $(12,13)$.

Therefore, ketone bodies are the norm and are present in human blood at all times, albeit at very low concentrations.

Recent discoveries have revealed that ketones, such as acetoacetate (AcAc) and its precursor $\beta$-hydroxybutyrate $(\beta-\mathrm{HB})$, are not only viable fuel sources for all cells with mitochondria, including the brain $(14,15)$ but are also legitimate signalling molecules, eliciting advantageous changes in inflammation (16), cognition (17,18), oxidative stress (19) and more. Beyond pathology, ketones may also be a relevant metabolic fuel in the context of physical activity, improving athletic performance (20) and myocardial adenosine triphosphate (ATP) generation $(21,22)$.

It is important to note that the ketotic metabolic state for the most part of the history of humans was a physiological state. People had to move a lot, and the availability of food was not sufficient and guaranteed.

However, over the past 200 years, by increasing the consumption of simple carbohydrates, increasing energy consumption and changing lifestyles, ketosis has been an exceptional state of the body.

The first signs of ketone bodies in the body were found in the urine of diabetic patients in the middle of the 19th century. For a long time, it was believed that these were undesirable, even non-physiological by-products of incomplete fat burning. Based on this assumption, the well-known expression "fats burn in the carbohydrate furnace" was invented, which according to the current state and knowledge is considered to be obsolete.
Once considered "metabolic garbage," ketones have become the focus of significant efforts within the realm of cardiometabolic research.

Initially, a ketogenic diet was used only for the treatment of pharmacoresistant epilepsy in children. Back in the 1980s, exogenous intake of ketone bodies had already caught the attention of the field of sports medicine $(23,24)$. Later on, possible medical applications started to be discussed and compassionate use treatments were carried out using sodium $\beta \mathrm{HB}$ in various rare metabolic diseases, such as Multiple AcylCoA-Dehydrogenase Deficiency (MADD), PDHD, and hyperinsulinism (25-27).

Therefore, earlier clinical studies have focused on the use of "extreme" versions of ketogenic diets for the treatment of seizures in epilepsy and other conditions.

However, recent studies suggest that metabolic changes associated with the treatment of epilepsy, weight loss, metabolic syndrome and type 2 diabetes can be achieved with more gentle approaches. They are less restrictive of carbohydrates and proteins, and are, therefore, safer and easier to implement, also in other groups of patients (14).

A "well-formulated" ketogenic diet is generally characterised by a total carbohydrate intake of less than $50 \mathrm{~g} / \mathrm{d}$ and a moderate protein intake of approximately $1.5 \mathrm{~g} / \mathrm{d}$ per $\mathrm{kg}$ of reference weight (28). This typically increases circulating ketone bodies ( $\beta$-hydroxybutyrate (BHB) and acetoacetate (ACA) from concentrations that are typically less than $0.3 \mathrm{mM}$ into the range of nutritional ketosis, which for $\mathrm{BHB}$, we define as $0.5-3 \mathrm{mM}(29)$. This range is below the typical 5-10 $\mathrm{mM}$ range for $\mathrm{BHB}$ that occurs during prolonged fasting, and well below concentrations characteristic of ketoacidosis $(28,29,30)$. From the perspective of meeting energy demands, the reduced carbohydrate and moderate protein intakes necessarily make ketogenic diets high in fat.

Thus, ketogenic diets have been studied sporadically for over 100 years, however, over the past 15 years an increasing number of researchers have concluded that the process of keto-adaptation may be associated with a wider range of health benefits than just the treatment of epilepsy (30-54).

Increasing general and scientific interest in the KD has led to new areas of application being opened up. Despite contradiction with mainstream dietary guidelines, ketogenic diets may be beneficial for many health conditions, particularly the previously mentioned conditions related to mitochondrial impairment, which includes obesity (31,32), diabetes (33-34), cardiovascular disease (35-37), cancer $(31,39-47)$, neurodegenerative diseases (dementia, Alzheimer's, etc.) (40, 41, $48-51)$, and even aging $(52-54,55,56)$. 
In terms of trend diets using ketone bodies or the $\mathrm{KD}$, the appetite-reducing effect is one of the most commonly cited advantages (30).

The possible benefits of using a ketogenic diet for a wide range of different diseases are still being actively discussed.

Thus, a ketogenic diet simulates metabolic hunger, creating a glucose deficit.

However, in the case of a ketogenic diet (KD), ketones are formed from the fatty acids in the diet, not only from the body's own fat reserves.

The brain usually prefers to use glucose as the main source of energy. Glucose accumulates in the body, primarily in the liver, in the form of a special substance, glycogen. Glycogen forms an energy reserve, which can be quickly mobilised to compensate for sudden glucose deficiency, if necessary.

Some tissues, such as brain and red blood cells, depend on a constant supply of glucose. If the amount of carbohydrates obtained from the food is insufficient, the necessary concentration of glucose in the blood may be maintained for some time by the breakdown of glycogen by the liver. With a glucose deficiency in the body, glycogen under the influence of enzymes is broken down to glucose, which enters the bloodstream. If these reserves are also depleted, the liver starts the de novo synthesis of glucose, gluconeogenesis.

Glucose can also be obtained from proteins and some other sources (gluconeogenesis). However, after only about two weeks of food deprivation, protein reserves will be depleted solely because of the necessary supply of glucose to the brain, and death will inevitably occur (58).

During periods of starvation, however, when glucose is not sufficient, ketone bodies can replace glucose as the main source of energy for the human brain.This is a prerequisite for the body to survive long periods of starvation using fatty deposits, without carbohydrates during periods of hunger $(57,59)$.

In addition to supplying the brain, ketone bodies also play an important role in the metabolism of hunger to provide energy to the heart muscle, skeletal muscles and kidneys.

The heart and kidneys can also use ketone bodies as an energy supplement under normal physiological conditions. In adults, the liver can produce up to $185 \mathrm{~g}$ of ketone per day. The proportion of free ketone bodies is individually considered very different (60).

Based on $\beta$-hydroxybutyrate $(\beta \mathrm{HB})$, the normal concentration in the blood serum after meals is approximately $0.05 \mathrm{mmol} / \mathrm{l}$ and $0.4 \mathrm{mmol} / \mathrm{l}$ after an overnight fasting. After 2-3 days of fasting, the levels of $2-3 \mathrm{mmol} / \mathrm{l}$ can be reached. In case of prolonged fasting it can reach $7 \mathrm{mmol} / \mathrm{l}$, and in case of a strict ketogenic diet - it is possible to reach a concentration of $4 \mathrm{mmol} / \mathrm{l}(61)$.

If too many ketone bodies are formed, they accumulate in the blood and penetrate the urine. In medicine, this condition is called ketonuria, or acetonuria, and its common name is "acetone in the urine". It is very dangerous and can cause serious poisoning, and in the case of people with diabetes or small children it may lead to an acetonaemic coma.

Healthy people have acetone in their urine when they are overworked and hypothermic, and the energy is used more quickly than it is replenished.

A ketogenic diet forces the body to use fats as the main source of energy. Usually, carbohydrates from food are processed into glucose, which is essential for the nourishment and functioning of the brain. However, if the diet contains little carbohydrates, the liver converts fat into fatty acids and ketone bodies. Ketone bodies enter the brain and are used as an energy source instead of the glucose.

\section{KETOSIS AS A RESULT OF A DIET WITH HIGH FAT CONTENT AND LOW CARBOHYDRATE CONTENT}

In addition to the already mentioned method of increasing the concentration of ketone bodies in the blood serum due to starvation, this can also be achieved by intensive physical activity.

However, there is a possibility of a targeted diet with a very high fat content and very low carbohydrate content (High Fat Low Carbohydrate, HFLC) (66).

Typically, if the consumption of carbohydrates exceeds $100 \mathrm{~g}$, no significant increase in ketone bodies in the blood (ketosis) should be expected. An increase is only possible with an intake of up to $40 \mathrm{~g}$, however, there are strong personal differences in this regard (60).

Frequently, a maximum carbohydrate level of $50 \mathrm{~g}$ per day also causes ketosis (65).

Physiological ketosis, which also occurs during a ketogenic diet (KD), must be clearly differentiated from pathological ketoacidosis, such as diabetes mellitus.

In case of a dietary ketoacidosis, maximum ketone body concentrations of up to $7-8 \mathrm{mmol} / \mathrm{l}$ are achieved, whereas in diabetic ketoacidosis concentrations can rise above $25 \mathrm{mmol} / \mathrm{l}$.

The target ketosis (the desired concentration of the ketone body in the blood) in the context of such a diet varies from 2 to $7 \mathrm{mmol} / \mathrm{l}$ and can only be achieved if strict dietary requirements are met (5).

Depending on the references, there are also values in the range of $3-5 \mathrm{mmol} / \mathrm{l}$ or $2-5 \mathrm{mmol} / \mathrm{l}$ (according to S1's KD recommendations) $(64,67)$. 
In addition, in the case of physiological ketosis, there is no glucosuria (urinary glucose) associated with hyperglycemia and concomitant reduction of plasma $\mathrm{pH}(59,62)$.

\section{When using ketogenic diets, an important consideration is also given to the concept of the ketogenic ratio.}

The ketogenic ratio is the ratio between fat and carbohydrate/protein content in the diet. In a classic ketogenic diet, the ratio is 4:1, perhaps even 3:1.

Thus, per $1 \mathrm{~g}$ of carbohydrates + proteins (in total), it is necessary to obtain $4 \mathrm{~g}(3 \mathrm{~g})$ of fat with food.

The common assumption that any of the lowcarbohydrate diets leads to a significant increase in ketones in the blood is not true. Regardless of the level of carbohydrates in low-carbohydrate diets, protein intake is usually too high and the amount of fat is too low (57).

Some proteins, or, more precisely, certain amino acids, can be metabolised to glucose and thus prevent ketogenesis. These "glucogenic" amino acids make up to $58 \%$ of the dietary protein $(58)$.

The main area of application and recognised indications for ketogenic diets.

Pharmacoresistant epilepsy in childhood and adolescence. Epilepsy is a complex condition that makes a child susceptible to seizures. Seizures result from abnormal electrical activity in the brain: Some parts of the brain get over-excited and fire off too many electrical signals. Treatments for epilepsy have expanded greatly in recent years to include many new medications, specialized diets and a wide range of surgical strategies. (70). If there is no effect from the treatment of two or more professionally used anticonvulsants, ketogenic diet can be assigned. Diet therapy can sometimes be a good option for childhood epilepsy when medications don't control seizures or cause intolerable side effects. It can be especially helpful for certain types of epilepsy, such as myoclonic astatic epilepsy (Doose syndrome). The mid-term effects of a classic ketogenic diet in children are comparable with modern anticonvulsants (Levy et al., 2012). Some cases (about 10\%) show pharmacoresistant (also refractory) epilepsy, which cannot be adequately controlled by drugs (68).

In these cases, $\mathrm{KD}$ (the ketogenic diet) is a good option $(67,68)$, and its short- and medium-term effects in children, according to Cochrane reviews, are comparable to those of modern anticonvulsants (73).

A modern approach to epilepsy provides diet therapy despite a good pharmaceutical therapy success. A number of different diets can be used for epilepsy. These include the Classic Ketogenic Diet (CKD), the Modified Atkins Diet (MAD), the Medium Chain
Triglyceride Diet (MCTD) and the Low Glycemic Index Treatment Diet (LGITD). Which diet is best for child will depend on the epilepsy diagnosis, child's age and eating habits, and family needs and preferences. It is possible and sometimes helpful to transition between the various diets.

Diet therapy takes a strong commitment, but it may offer children a better chance of seizure control than trying a new medication. Because there isn't yet a good way to tell exactly how a child will respond to diet therapy, a trial of three to four months is usually recommended.

The ketogenic diet has been shown to be effective for many children with epilepsy when drugs fail. It can provide control of seizures for about 30 percent of children with epilepsy. The mechanism of action of KD in epilepsy is still unclear. There are many suggestions as to why this dietary treatment is showing good results (67). In addition to the assumption that ketone bodies are responsible for anticonvulsant properties, there is evidence of the anticonvulsant effects of some fatty acids (capric acid, C10) (70,71, 72).

In its strictest form, the ketogenic diet (CKT) provides more than 90 percent of its calories through fat (compared to the 25 to $40 \%$ usually recommended for children). When the body burns fat for energy, rather than glucose from carbohydrates, it produces compounds known as ketone bodies. The increase in ketones is called ketosis. Experts believe ketosis reduces seizure activity in the brain, although exactly how this works is still unknown.

Though the diet is challenging, it's easier than it used to be. As interest in the diet has increased, "ketofriendly" products have become more widely available. These include coconut oil, low-carbohydrate noodles, sugar-free syrups and flavorings, and nut flours.

Nowadays, the use (CKT) in epilepsy is mainly limited to the childhood period. However, good therapeutic results are also reported for adults (74). Similar side-effects (hypoglycemia, excessive ketosis, etc.) have been described in children and adults during (CKT), but adolescents and adults have a higher tendency to not follow this complex diet therapy (74).

Because of easier use, adolescents and adults prefer MAD (modified Atkins' diet) to the CKT (69). Overall, the adult refusal rate is more than $50 \%$ for the classic diet (CKT) and an average of $28-42 \%$ for $\operatorname{MAD}(69,74)$.

Ketogenic diets have also been used to treat rare brain energy metabolic defects, such as Glut1 and Pyruvate dehydrogenase deficiency (PDHD) deficiencies.

The first description of the GLUT1 deficiency syndrome was made in 1991 (75). The glucose transporter type 1 (Glut 1 ) is the most important energy 
carrier of the brain across the blood-brain barrier. In the early nineties, the first genetic defect of Glut 1 was described and known as the Glutl deficiency syndrome (Glut1-DS). It is characterised by early infantile seizures, developmental delay, microcephaly, and ataxia. Recently, milder variants have also been described. The clinical picture of Glut defects and the understanding of the pathophysiology of this disease have significantly grown. A special form of transient movement disorders, the paroxysmal exertion-induced dyskinesia, absence epilepsies particularly with an early onset absence epilepsy and childhood absence epilepsy, myoclonic astatic epilepsy, episodic choreoathetosis and spasticity, and focal epilepsy can be based on a Glut1 defect.

The use of KD is based on the fact that ketone bodies pass through the hemato-encephalic barrier through another receptor (MCT1) and thus serve the brain as a substrate for alternative energy. The treatment is usually done using classic $\mathrm{KD}$ with a ratio of $3: 1$ or $4: 1$. Over the last few years, there has been growing evidence that MAD is also suitable for the treatment of GLUT1 deficiencies $(76,77)$. MAD can also be used for adult patients or in case of non-compliance. There is not yet enough data for such statements to be made about the LGIT or MCT $\operatorname{diet}(77)$.

Pyruvate dehydrogenase deficiency (PDHD) is a rare neurometabolic disorder characterised by a wide range of clinical signs with metabolic and neurological components of varying severity. Manifestations range from often fatal, severe, neonatal lactic acidosis to later-onset neurological disorders.

Pyruvate, the final product of glycolysis, can only be metabolised to acetyl-CoA for a limited energy use in the citric acid cycle $(76,78)$. The consequences of this disorder include, but are not limited to, increased lactate (hyperlactatemia) and lack of energy (78). The neurological type is characterised by lesions of the brain and nervous system. However, it is worth noting that the isolated form of the disease is extremely rare. As a rule, patients are found to have a transient type of the disease, which is manifested by neurological and metabolic disorders.

The KD bypasses the pyruvate dehydrogenase reaction. Acetyl-CoA, which is essential for the citric acid cycle, is formed from fats rather than the glucose (76). In general, a KD is a safe and effective treatment for most PDG patients (Pyruvate dehydrogenase deficiency (PDHD) (78).

Ketones may be an alternative energy supply for the reduced glucose transport through the hematoencephalic barrier (Glutl defeciency) or impaired glucose degradation (PDH deficiency) and thus effectively treat emerging epileptic encephalopathy (79).
New ketogenic diets are becoming increasingly popular (57):

- in older children, adolescents, in cases of problems with compliance with treatment requirements;

- therapy for neurodegenerative diseases and craniocerebral injury (Masino and Rho, 2012);

- weight loss in adults.

Increased central nervous system energy reserves lead to higher neuronal resistance, a reduction in free radicals and a decrease in inflammatory activity, which makes it possible to use ketogenic diets more widely. Ketogenic diets are performed under medical supervision and are achieved only in the team of the patient, parent, pediatrician and specialist nutritionist.

It is necessary to calculate the ratio of LPG individually and to add carbohydrate-free additives (vitamins, minerals, trace elements) in all ketogenic diets.

The ketogenic diets are not currently recommended for adults (57).

\section{DIFFERENT TYPES OF KD DIETS}

In clinical use, the general term "ketogenic diet" includes four diets $(80,81)$ :

- the modified Atkins Diet (MAD),

- MCT (medium-chain triglyceride diet), triglycerides with a medium chain length,

- low glycemic index treatment (LGIT),

- a classic ketogenic diet.

Recently, ketosis has been increasingly reported as a possibility for some forms of intermittent fasting (intermittent fasting 5:2), but usually it is not considered to be a ketosis diet (82).

\section{THE MODIFIED ATKINS DIET (MAD)}

The Atkins diet was developed by an American doctor Robert Atkins in 1972 and published under the title "Dr. Atkins diet revolution". Atkins advocated a diet in which the carbohydrate consumption was extremely limited, but one could eat proteins and fatty foods, such as meat, fish, sausage, cheese and eggs as one wished. In the initial stage of this diet, only $5 \mathrm{~g}$ of carbohydrates (83) are released daily.

In the modified Atkins diet, which is used as a ketogenic diet, this amount is about $10-15 \mathrm{~g}$ of carbohydrates per day.

This diet is more commonly used for children and adolescents in the early stages.

For adults, the daily starting amount is 20 grams of carbohydrates. No ballast substances are included in the calculation of the carbohydrate consumption, but sweet alcohols (xylitol, sorbitol, erythritol) are part of it. 


\section{KETOGENIC DIETS IN COMPARISON (57)}

\begin{tabular}{l|l|l|l|l}
\hline Diet type & Fat content \% & Protein content \% & Carbohydrate content \% & $\begin{array}{l}\text { Protein to carbohydrate } \\
\text { ratio }\end{array}$ \\
\hline Classic ketogenic diet & 90 & 6 & 4 & $4: 1$ \\
\hline $\begin{array}{l}\text { modified Atkins Diet } \\
\text { (MAD), }\end{array}$ & 64 & 30 & 6 & $5: 1-2: 1$ \\
\hline MCT & 73 (incl. 30-60\% MCT oil) & 10 & 17 & $1.2: 1-1.6: 1$ \\
\hline $\begin{array}{l}\text { Low glycemic index treat- } \\
\text { ment (LGIT) }\end{array}$ & 60 & 30 & 10 & $1: 1$ \\
\hline Regular diet & 35 & 15 & 50 & $0.3: 1$ \\
\hline \begin{tabular}{l} 
CKD: classic ketogenic diet; \\
\hline
\end{tabular} & MAD: modifed Atkins diet; & $\begin{array}{l}\text { MCT: medium chain triglyc- } \\
\text { erides diet; }\end{array}$ & $\begin{array}{l}\text { LGIT: Low Glycemic Index- } \\
\text { Treatment }\end{array}$ & \\
\hline
\end{tabular}

When doing the MAD, there is no indication as to which carbohydrates should be consumed predominantly. However, it is recommended to choose food with predominantly complex carbohydrates.

At a later stage, depending on the clinical picture, the carbohydrate consumption can be gradually increased to a maximum of $60 \mathrm{~g} /$ day. The protein consumption is not limited with the MAD and can reach up to $30 \%$ energy consumption (84).

The ketogenic ratio of the modified Atkins diet is

\section{1: 1 to $1.5: 1$.}

The ketosis achieved with this form of diet is usually lower than with a classic ketogenic diet, but this diet is also good for the treatment of pharmacoresistant epilepsy (85). The calculation of meals is much simpler and the time spent on learning and using the diet at home is shorter because only carbohydrates are counted.

\section{MCT DIET, USING THE MCT OIL ( MEDIUM-CHAIN)}

Medium Chain Triglycerides (MCT) are a type of synthetic dietary fat first produced in the pharmaceutical industry from coconut oil in the 1950s for the treatment of patients unable to digest conventional fats. Having been used so far for medical purposes, the MCT oil has also become a popular fitness supplement, which is advertised as a fat burner, muscle growth accelerator and energy source.

Medium chain triglycerides consist mainly of fatty acids with 8 and 10 carbon atoms (medium chain fatty acids, MCFA).

MCT (or MCT-fats) are triglycerides that contain fatty acids with medium chain lengths. Unlike longchain fatty acids, MCTs can be absorbed in the intestine independently of bile acids and pancreatic lipases.

From the small intestine, they are transported through the blood directly to the liver. There they are preferably oxidised in comparison with conventional fats and have a higher ketogeneity than long-chain triglycerides (LCT).

The term "ketogenicity" refers to the rate of formation of ketone bodies, which varies depending on the initial fat $[86,87]$.

Fatty acids with an average chain length include capron (C 6: 0), caprilic (C 8: 0), caprilic (C 10: 0) and lauric acid (C 12:0). No pure MCT fat is found in nature.

For example, coconut fat contains $60 \% \mathrm{MCT}$, milk fat $10 \%$ MCT.

Commercially available MCT fats are usually extracted from coconut fat or palm kernel oil. At the same time, MCT fat is available in the form of transparent, tasteless oil, margarine and drinkable emulsion for therapy. (Table 2).

MCT oils and fats are usually prescribed for lipid metabolism disorders, malabsorption of fats associated with diseases (e.g., pancreatic insufficiency, short intestinal syndrome) and KD. It is also prescribed for parenteral nutrition. They are also very popular among athletes.

In comparison, structurally shorter MCTs $(8.4 \mathrm{kcal} / \mathrm{g})$ have a $10 \%$ lower energy content than long-chain fats $(9.3 \mathrm{kcal} / \mathrm{g})$ [88]. On the packaging of MCT products, information on the nutritional value is given in accordance with the EU Regulation $1169 / 2011$ with $9 \mathrm{kcal} / \mathrm{g}$ or $37 \mathrm{~kJ} / \mathrm{g}$. Fat differentiation is not provided here (89).

Since MCT fats can cause gastrointestinal discomfort, it is recommended to slowly increase their amount. Infants and young children start at $1 \mathrm{~g} / \mathrm{kg}$ body weight, older children and adults start at 10-20 $\mathrm{g} /$ day, and then increase the amount in several steps to the desired daily dose.

As early as 1971, HuttenlocHer et al investigated the effectiveness of MCT fats in a ketogenic diet in 12 children. Patients received $60 \%$ of the required energy in the form of MCT fats. 
This corresponded to more than $100 \mathrm{~g}$ of MCT fat per day.

Children were given MCT oil mixed with low-fat milk three times a day for the main meals. The benefits of such a diet with the MCT were described as follows: "MCT fats lead to ketosis faster, so the carbohydrate content in the diet does not need to be reduced so much, the efficiency is comparable to a ketogenic diet in a ratio of 3:1. Compatibility is better and implementation is easier. (87)

The MCT diet, according to some researchers, has a comparable effect to the classic $\mathrm{KD}(90,91)$. Today, an even distribution of MCT fats is recommended for all meals $(91,92)$.

\section{LOW GLYCAEMIC INDEX THERAPY ( $L G \| T$ )}

The term glycemic index (GI) was used in 1981 by Jenkins et al. GI is a calculated value representing the increase in the blood glucose concentration (calculated as an area under the curve) after a certain amount $(50 \mathrm{~g})$ of food intake compared to the reference (glucose or white bread). Consequently, products with high GI (simple sugars) result in higher blood glucose concentrations than products with low GI (complex carbohydrates) $(93,94)$.

A low glycemic index therapy was developed by Pfeifer and Thiele in 2002 in Boston. This form of ketogenic diet only uses food with a glycemic index of $<50$. Although the name suggests that no carbohydrate counting is required, this cannot be supported in practice.

With such a low carbohydrate diet, as is the case with the MAD, it is necessary to calculate and maintain the daily amount of carbohydrates.

In general, about $40-60 \mathrm{~g}$ of carbohydrates are allowed per day. Even with this form of the nutrient therapy, it is reported that seizures in epilepsy have decreased (95).

\section{| NTERMITTENT FASTING DIET $(5: 2)(I F D)$}

Intermittent fasting is a new trend in weight loss. With time-restricted feeding (TRF), food can only be supplied at certain intervals [96]. Instead of fasting for several consecutive days, short periods of not eating for one day ( 8 hours of eating, 16 hours of fasting) or for a week (diet 5: 2:5 days of eating, 2 days of fasting) are applied.

In this case, the daily meal break, which is natural due to a night's sleep, is already an overnight-fasting (OF). The time-restricted feeding TRF (97) is achieved by expanding the overnight fasting (OF).
The best known method is the 16:8 method, which means a total of 16 hours of fasting and eating for only 8 hours per day (96).

Alternate-day fasting (ADF) offers a restriction of meals every second day. Thus, with ADF, you should fast on one day, and can eat an unlimited amount of food the next day.

The IF method: 5:2 means that a person eats regularly 5 days a week and fasts or severely limits energy for the remaining 2 days (96).

The 5:2 diet is best known due to Dr. Michael Mosley ("The fast diet"), alternate-day fasting (ADF) due to Dr. Krista Varady ("The every other day diet") and Harvie's 2-day diet due to the books which have been published since $2013(98,99,100)$. In the case of intermittent fasting, ketosis is achieved only in some types, namely for the 5:2 type (115).

Positive metabolic changes in the case of intermittent fasting are caused by the conversion of metabolism from a predominantly carbohydrate to lipid metabolism. There is an increase in the mobilisation of free fatty acids from fatty tissue. They are used to form ketone bodies in ketogenesis. Ketone bodies are then used by some organs and the brain after the adaptation phase as an alternative energy substrate to glucose (instead of glucose).

$\beta$-hydroxybutyrate $(\beta \mathrm{HB})$ is the main ketone body for the energy supply $(101,102)$. Since ketogenesis begins after a brief fasting, it is possible that the formation of ketone bodies during the intermittent fasting has a decisive influence on the positive effects proven in the studies.

This form of nutrition is also of interest in the study of hormone levels (glucagon, insulin), free fatty acids and glycogen storage.

There is growing evidence that $\beta \mathrm{HB}$ is not only an energy carrier, but also performs signaling functions on the cell surface and inside the cell, which, for example, affect gene expression, lipid metabolism, neuronal function and metabolic rate $(103,104)$.

Some researchers (115) believe it is possible to influence a number of diseases in humans, such as type 2 diabetes mellitus, Alzheimer's dementia, through these molecular signaling functions.

To better understand the metabolic situation of short-term intermittent fasting in humans, a nutritional intervention study was conducted that examined the effect of the intermittent fasting on ketogenesis using the 5: 2 method (115) as an example.

The study concentrated on a brief change in the $\beta \mathrm{HB}$ concentration in the capillary blood during 2 days of fasting with complete energy limitation during the intermittent fasting using the 5: 2 diet (106-108, 109-112). On the days of fasting, there was a notice- 
able increase in the $\beta \mathrm{HB}$ level in the blood, which was not observed on other days.

On the second day of fasting, ketone bodies appeared in the blood (up to 2-3 $\mathrm{mmol}$ per liter). The data usually shows the ketone body level rise by $30-50 \%$. Moreover, there is a rather large difference in values $(113,114,115)$.

With other forms of intermittent fasting, for example, 16/8, 14/10,24/0 there is no significant increase in the production of ketones.

Due to the high hopes that some dieticians and sports physicians have today for the intermittent fasting, it is of great interest to researchers to compare different forms of diet in terms of the weight loss $(116,117,118)$.

Intermittent fasting helps reduce weight and can contribute to good health, but not better than regular diets (116). This is the conclusion reached by the scientists from the German Cancer Research Centre (DKFZ) and the Heidelberg University Hospital (Deutsches Krebsforschungszentrum und das Universitätsklinikum Heidelberg) in the HELENA study (HELENA-Studie) (116), the largest study in this area to date. It is obvious to researchers that there are many different ways to reduce weight, but it is important to select the right option for each patient.

The HELENA study conducted by a team of scientists from the DKFZ and the Heidelberg University Hospital examined 150 overweight and obese people for one year. The patients were randomly divided into three groups: one third had a regular diet for 12 weeks. Energy consumption was reduced by $20 \%$. The second group was on a 5:2 diet, but they also received $20 \%$ less energy.

The control group did not follow a specific diet plan, but like all the other participants, was motivated to follow a balanced diet as recommended by the German Food Society (DGE). After the actual phase of the diet, the scientists tracked the weight and health status of the study participants for another 38 weeks.

The result was unexpected given the high expectations for the intermittent fasting: the health status improved equally in both groups (weight loss, visceral fat, and unhealthy abdominal fat and liver fat deposits).

The changes in the distribution of fat in the participants' bodies were precisely determined by a special MRI performed at the Heidelberg University Hospital. At the same time, the research has shown that with a weight loss of only $5 \%$, about $20 \%$ of abdominal fat and even more than a third of liver fat is lost, regardless of a diet type.

There was also no difference between the two diets in all other metabolic values and in all the biomarkers and gene activity studied.
Although the HELENA study does not support euphoric expectations of for the intermittent fasting, it also shows that it is not worse than common diets for weight loss.

This method requires further observation, especially since there is evidence of a possible relationship between the intermittent fasting and family eating disorders.

\section{THE CLASSIC KETOGENIC DIET (CK D)}

According to the classic ketogenic diet (CKD) each meal including appetizers should contain a desired proportion of fat to carbohydrate/protein.

The basis of calculation for the classic ketogenic diet was designed in 1924 by Dr. Peterman, the doctor of Children Mayo Clinic. The ratio of diet composition, published by Peterman contained $1 \mathrm{~g}$ of protein on 1 kilo of a body weight $(10 \mathrm{~kg}), 10-15$ г carbohydrates per day and the rest energy was received from fat (119). To date, the proportion of fat in the ratio is given as a ketogenic proportion.

Ketogenic diet (KD), offered by Peterman has already had correlation 4:1, which meant four 4 grams of fat for every 1 gram of protein and carbohydrates. Each food intake should have a selected concentration. As a result it takes some efforts to calculate and apply the classic ketogenic diet (120).

For children older than 2 years of age the ratio $4: 1$ is generally recommended.

For children younger than 2 years of age as well as for children with good response to KD related to a strong ketosis or difficulties in sustaining, the ratio 3:1 may be established. (67).

In the classic ketogenic diet (CKD) weight proportion between fats and proteins is 4 to 1 (but when using this diet for weight loss the coefficient is shifted toward increasing proteins and reducing fats). Thus, the foods high in carbohydrates, such as sweet fruits and vegetables, bread, pasta, grains and sugar are removed from the ratio whereas the intake of products rich in fats such as cheeses and butters is increased.

Ketosis is explained as an increase in the level of ketone bodies in blood that reduces the incidence of epileptic seizures.

Liver in a child accumulates less glycogen than in an adult. Therefore a child body recognises earlier a deficit of glucose and resorts to fat storages. Ketone bodies in urine of newborns often show that a child is malnourished. A basic diet for children with epilepsy contains the necessary amount of proteins for growth and regeneration of the body and an adequate amount of calories to support a normal body mass (in accordance with the age and height). 
Most fats consumed with the food comprise long chain fatty acids (LCFA) However, from the point of view of using $\mathrm{KD}$ medium chain fatty acids (MCFA) are more appropriate. In one variant of the ketogenic diet a sort of coconut oil is used, which is rich in medium chain fatty acids (MCFA) and covers a half of a daily calorie intake.

\section{COMPARISON OF DIFFERENT VARIANTS OF DIETS}

Table 1 presents different types of ketogenic ratios with their compositions proportional (\%) to amount of energy. There are a classic ketogenic diet, MCT diet, modified Atkins diet, Glycemic Index diet and a diet recommended by DGE (57).

Table 1. Legend: $D G E=$ German Nutrition Society; $K D=$ ketogenic diet; LGIT = Low Glycemic Index-Treatment; MAD = modified Atkins diet; $M C T=$ medium chain triglycerides

\begin{tabular}{l|l|l|l}
\hline Diets/composition \% & Fats\% & Protein\% & Carbohydrates \% \\
\hline Classic KD 4:1 & 90 & 6 & 4 \\
\hline MCT Diet & 73 & 10 & 17 \\
\hline MAD & 65 & 35 & 5 \\
\hline LGIT & 60 & 30 & 10 \\
\hline Diet recommended by DGE & 55 & 15 & 30
\end{tabular}

Comparison of nutrition value among different ketogenic diets and the nutrition recommended by DGE (provided from recommended protein consumption as well as recommendation amounts for carbohydrates and fats) in energy percentage (En\%) $(68,69,32)$.

Thus, all KD are extremely high-fat diets, which nevertheless differ on their compositions and a range of effect. In case of a milder diet it is possible to eat more protein, which simplifies the diet and makes it similar to a normal diet.

The stricter is the diet, the higher ketone level is achieved. But it should be kept in mind that assignment to such a diet affects the taste and social integration.

Special attention should be paid to regular foods that contain certain ketone values. They are shown in Table 2 (57)

\section{UNDESIRABLE EFFECTS}

Ketogenic diet is usually well tolerated by children and if administered under medical supervision in accordance with standardized protocol and supervision of an experienced nutrition team it is considered a safe diet therapy. (120).
Table 2.

\begin{tabular}{l|l}
\hline Content in foods & $4: 1$ and more \\
\hline Pork fat & $30,5: 1$ \\
\hline Melted butter & $30,5: 1$ \\
\hline Mayonnaise (80 \% fat) & $23,6: 1$ \\
\hline Brazil nuts & $9,6: 1$ \\
\hline Salad Mayonnaise (50 \% fat) & $9,5: 1$ \\
\hline Sour cream (24\% fat) & $6,1: 1$ \\
\hline Macadamia nuts & $5,7: 1$ \\
\hline Cream (30\% fat) & $5,6: 1$ \\
\hline Mascarpone & $5,4: 1$ \\
\hline Black olives & $5,0: 1$ \\
\hline Coffee cream (30 \% fat) & $4,7: 1$ \\
\hline Content in foods & $3: 1$ bis 3,9:1 \\
\hline Coconut & $3,9: 1$ \\
\hline Coconut, meat & $3,9: 1$ \\
\hline Walnuts & $3,2: 1$ \\
\hline Pecan & $3,1: 1$ \\
\hline Content in foods & $2: 1$ bis 2,9:1 \\
\hline Green olives & $2,9: 1$ \\
\hline Hazelnut & $2,8: 1$ \\
\hline Avocado & $2,6: 1$ \\
\hline Almond flour & $2,4: 1$ \\
\hline Meat sausage & $2,3: 1$ \\
\hline Almond drink (without sugar) & $2,2: 1$ \\
\hline Meatloaf & $2,1: 1$ \\
\hline Cottage cheese & $2,0: 1$ \\
\hline Content in foods & $1: 1$ bis 1,9:1 \\
\hline Tuna in oli & $1,9: 1$ \\
\hline Gouda, min. $60 \%$ fat & $1,9: 1$ \\
\hline Meatloaf 1,8:1 & $1,8: 1$ \\
\hline Almond 1,8:1 & $1,8: 1$ \\
\hline Sesame & $1,6: 1$ \\
\hline Eel & $1,6: 1$ \\
\hline Boiled sausage & $1,5: 1$ \\
\hline Salami & $1,5: 1$ \\
\hline Gouda, min. $45 \%$ fat & $1,4: 1$ \\
\hline Black olives & $5,0: 1$ \\
\hline Coffee cream (10\% Fett) & $1,4: 1$ \\
\hline Herring & $1,0: 1$ \\
\hline
\end{tabular}

Potential side effects occurring in the beginning of the application as well as during a long-time apllication are shown in Table 4. Besides, possible causes and symptoms additional countrameasures are offered.

Especially in the initial phase such side effects as nausea, food refusal or hypoglycemia are quite common. But they seldom occur later. In general possible 
side effects are not meaningful, can be easily cured and differ from person to person. (122).

The effect of a decreased appetite has been also discussed in favour of using the diet for weight loss. Obese adults assigned to a modified ketogenic diet felt less hungry and ate less. $(123,124)$.

Of interest there are findings associated with blood lipids and blood glucose level. Improvement in triglyceride, cholesterol and glucose levels in the blood was observed in obese patients even in a 24-week study $(125,126)$.

Further comments on these effects are not possible until they studied further. In some cases, which are detailed described in the instruction $S 1, \mathrm{KD}$ is strictly forbidden and causes severe and even irreversible side effects (67). Thiamine pyrophosphokinase deficiency serves as an example. A severe metabolic acidosis and irreversible neurological damage caused by $\mathrm{KD}$ were reported. (127). Therefere before starting a KD, a medical consultation is required.

\section{SIDE EFFECTS}

Thus, the ketogenic diet is the diet with a high content of fats and low conternt of carbohydrates. Different studies are unanimous on using KD for treatment of pharmacoresistent epilepsy when its three forms such as classic ketogenic diet, modified Atkins diet and MCT diet showed relatively equal success in reducing seisures. (57).

Anyway, significant efforts are needed to teach the application of ketogenic diet, introducing it to the daily routine since each meal has to be planned individually. For instance, a spontaneous lunch with friends at a cantine or a restaurant will be impossible without a thoroughul planning.

Due to limitation of carbohydrates contained in fruits and grains, which are allowed in very small amounts, there is a risk of developing a deficiency of vitamins and minerals.

There are no standard recommendations on substitution because the consumption is calculated individually for each patient in accordance with the protocol and when necessary a corresponding medication is prescribed. Since food preferences change often in childhood, the calculation protocol should be revised each 3-6 months. (57).

\section{KETOGENIC DIETS FOR CANCER TREATMENT}

Recently, the possiblility of using diets with low carbohydrate content for cancer patients has been widely discussed. As a justification for using ketonic diets it was indicated that metabolism of tumor cells depends on carbohydrates.
Depening on interpretation of the data, these diets either promise a direct influence on growth of the tumor or its metastasis, improve efficiency of chemotherapy or radiation therapy. Sometimes, scientists promise better tolerance of the treatment, particularly, the chemotherapy $(128,129,130)$. However, the review carried out by Nicole Erickson and coauthors (131), showed an absolute contraindication of using isocaloric ketonic diets in cancer patients due to reduction of weight and consequent worsening of the prognosis.

The study surveyed 15 researches $(8$ prospective researches, 2 retrospective researches, 5 cases), which comprised 330 patients with malignant tumors.

Since there is no homogeneity in types of tumors, their localization and stages, the results of the study could not be fully compared. The points of comparison for 15 researches were: quality of life and the toleration of the diet wheras antitumor effect was not considered.

Moreover, none of the studies showed tumor regression, better survival and better tolerance of the therapy or reduction of KD side effects. (132).

The German nutrition team «Working Group on Prevention and Intergrative Oncology" (PRIO) of the German Cancer Society (DKG) (131) states that presently there are no human subject researches demonstrating that ketogenic diet or low carbohydrate diet allows (130):

- to prevent or suppress growth or metastasis in human;

- to enhance efficience of chemotherapy or radiation therapy;

- to improve tolerance of chemotherapy.

Therefore, based on the data in disposal it is not recommended to use low carbohydrate or ketogenic diet for cancer treatment.

Specialists often indicate possible side effects of such diets in cancer patients,

Documented side effects include: nausea, loss of appetite, loss of weight, constipation, hyperlipedimia, artherosclerosis, hypercholesterolemia, absence of thirst, kidney stones, pancreatitis, dehydratation, selenium deficiency and drowsiness. $(133,134,135)$.

Such side effects due to the diets are hard to distinguish from consequences of cancer or its therapy. Ketogic diet carried out without supervision of an oncologist may lead to serious errors in the therapy.

Ketogenic diet and low carbohydrate diets may facilitate malnutition in cancer patients. Fine et al. observed already in 2013 reduction of weight by $4 \%( \pm 6,1 \%)$ in cancer pationts who were 28 days on ketogenic diet. 
Table 3. Symptoms, Causes and solutions on administering KD (57)

\begin{tabular}{|c|c|c|}
\hline Symptoms & Causes & Solutions \\
\hline $\begin{array}{l}\text { Apathy, reduction of } \\
\text { attention }\end{array}$ & $\begin{array}{l}\text { Effects of ketone bodies on the central } \\
\text { nervous system }\end{array}$ & After the adaptaion to the changes the symptoms are normally disappear. \\
\hline Nausea and vomiting & Lack of carbohydrates & $\begin{array}{l}\text { Under a very high levels of ketones small amount of carbohydrates can be } \\
\text { administered }\end{array}$ \\
\hline Hypoglycemia & Lack of carbohydrates & Small amount of carbohydrates can be administered. \\
\hline Decreased appetite & $\begin{array}{l}\text { - signs that ketone bodies produce a } \\
\text { damping effect on hunger sensation; } \\
\text { - another reason might deal with } \\
\text { exposure to unfamiliar food (phase of } \\
\text { transition) }\end{array}$ & $\begin{array}{l}\text { - one missed food intake is irrelevant to success of the therapy and can be } \\
\text { rescheduled; } \\
\text { - food intakes should be planned according to the preferences of the } \\
\text { patient; } \\
\text { - to stimulate the consumption through visually appetizing food; }\end{array}$ \\
\hline Constipation & insufficient intake of fiber and liquids & To ensure an adequate intake of liquids \\
\hline diarrhea, stomach spasms & $\begin{array}{l}\text { Excessive intake of fat or excessive } \\
\text { consumption of TMC }\end{array}$ & $\begin{array}{l}\text { Under excessive intake of long chain fatty acids one part can be replaced } \\
\text { with MCT fats. }\end{array}$ \\
\hline
\end{tabular}

Table 4. Complications during long-term KD assignment (57)

\begin{tabular}{l|l|l}
\hline Hyperlipidemia & $\begin{array}{l}\text { Too many animal products with high fat content and conse- } \\
\text { quntly too high consumption of saturated fatty acids }\end{array}$ & $\begin{array}{l}\text { Careful selection of fats (training in fats /oils), preference } \\
\text { of oils, if possible MCT fats }\end{array}$ \\
\hline Kidney stone disease & Hypercalciuria, inadequate fluid intake & To control fluid intake \\
\hline
\end{tabular}

Tan-Shlalaby et al. reported that $73 \%$ of patients lost in average 7,5 $\pm 5,8 \mathrm{~kg}$ of body mass during a 16 week ketogenic dieting (137).

Urbain et al. (2017) reported on loss of weight by $2,0 \pm 1,9 \mathrm{~kg}$ of the body mass in healthy volunteers on ketogenic diet, though their average consumption of energy has not changed confirming earlier evidences that isocaloric ketogenic diets facilitate loss of weight due to metabolic changes (138).

The menioned loss of weight is known due to investigations aimed at intensive medical support of patients. Nevetheless the loss might be more dangerous for patients assigned to the diets under questionable conditions (for example without blood control).

Therefore, basing on the latest data low carbohydrate or ketogenic diets can be recommended neither as a complementary therapy nor as a nutrition pattern for cancer patients.

The patients who are interested in low carb or ketogenic diets should be as early as possible informed about possible negative consequences of such diets. Besides, the cancer patients who assigned to such diets should be found and persuaded to discontinue. If patients stick to low carbohydrate or KD inspite of intensive contraargumentation, it is necessary to subject them from the very beginning to a strict interdis- ciplinary supervision, including control of the weight, body composition, laboratory values (131).

\section{KETOGENIC DIET FOR REDUCTION OF WEIGHT (OBESITY)}

To date, more and more specialists refer positively to the diets with low carbohydrate content due to a negative experience to the ratios recommended currently for weight loss in the practice.

Nowadays, in Germany a mediterenean diet, DASH and vegetarian diets with limitation of energy are commonly recommended in the medical practice, but the data of their efficiency is limited (139).

Besides, the diets with lower content of fats did not demostrate that they are more effective for weight loss (140). Commercially available weight loss programs show a short-time success in reduction of sugar level (in glycemic control), yet a long-term success during one year is rare (141).

The official point of view on KD and the effect of ketone bodies in terms of health benefits is rather contradictional (142).

Certain works found definite advantages of $\mathrm{KD}$ for weight loss, however other works did not find advantages compared to other diets. $(143,144)$. 
Neverthelss a current consensus admits that KD decreases appetite and patients feel themselves less hungry compared to other diets based on reduction of carbohydrates. Ketosis is considered responsible for this phonomenon (145).

Well-known medical institutions have currently started ambitious researches to provide additional arguments to change the paradigm. Therefore some specialists call on their colleagues to reconsider DGE recommendations and to ignore general nutrional recommendations (146).

E.g. Sarah Hallberg from Virta Health Centre, a branch of University in Lafayette in Indiana/USA advocates a sharp decrease in carbohydrate intake. By the way, there was no suprise that her article appeared in British Journal of Sport Medicine (147). Sport doctors were the first to stress that there is no actual need in carbohydrates (148).

Already in 1980s exogene consumption of ketone bodies became a subject of sport medicine. (149, 150). Later medical use of KD has been debated and independent therapeutical investigations were carred out, including the study of Natrium- $\beta \mathrm{HB}$ for rare metabolic conditions, such as multiple acyl-CoA dehydrogenase deficiency (MADD), PDH deficiency or hyperinsulinism (151-154).

Among others, intake of dietary supplements based on exogenous ketone body was described as a supporting and at the same time facilitating therapy during clinicialy feasible KD (152).

Hallberg's team (155) has recently published an impressive „proof of principle“: she compared a treatment of 262 patients with Type 2 diabetes with a limited daily carbohydrate ratio (up to 30 gram) aimed at achieving ketosis, with a conventional treatment of 87 control patients. After one yeat $\mathrm{HbAlC}$ values in the respondent group reduced from 7,6 to 6,3 , body mass decreased by $13,8 \mathrm{~kg}$. Whereas prior to the study such patients in $56,9 \%$ cases needed oral antidiabetic medications but after restructuring their nutrition the drugs were needed only $29,7 \%$ of cases.

Besides, $94 \%$ of the patients on diet did not need insulin therapy. The advantages were also evident in lipid metabolism as well as in serum creatinine and liver enzymes. In patients with daibetes who received a traditional therapy, biomarkers, medications and doses of insulin remained unchanged. (155).

Hallberg links a ratio with high carbohydrate contents to overweight, obesity, metabolic syndrome and type 2 diabetes (T2D). First of all it is meant to reduce the level of insulin secretion enabling not to suppress burning of fat but to stimulate it. Such regulation of lipolysis can be achived with the help of "very low carbohydrate/ketogenic diet"(VLCKD).
This is a kind of a medium position between a low carbohydrate content, which is also popular among healthy people, and a strict ketogenic diet, used for the treatment of epilepsy.

Thus, the ketogenic ratio with an intake of 20 to 50 grams of carbohydrates per day is discussed. Fats may contain $45 \%$ or more (it always depends on total amount of calories), proteins - about $40 \%$. Other research groups do not focus on percentage but calculate carbohydrates, proteins and fats based on body weight.

Specialists (146) indicate that on the initial stage of transition to a ketogenic diet the use of high-protein formula diets can be helpful. They have an advantage that patients do not need to think about cooking a meal and their benefits are seen promptly. The amounts are defined individually for each patient in accordance with his body weight so that carbohydrate intake corresponds to a diet with low or very low carbohydrate content. Additionally, consumption of olive oil and vegetable juices is recommended. During several days a formula diet is gradually replaced with a low carbohydrate ration, which is stipulated by instructions.

The target can be achieved not only in T2D patients, but also in people, only susceptible to overweight. According to a recently published research in Dusseldorf (156), where the use of an intervention program aimed at changing the way of life under supervision of a medical team led to a significant loss of weight and improved metabolic control in overweight patients at risk for diabetes.

The experts from Dusseldorf drove a conclusion from the findings of their 2-year-long study that about one-third of respondents are able to follow the diet with carbohydrate depletion. Half of those who stopped dieting (one-third of the whole group) managed to continue to loose weight.

Simular positive results were reported in some reviews $(157,158)$. Often there were no comprehensive definitions of how low the levels of carbohydrates were, whether ketone bodies were measured, what fat or protein levels were rationed; whether calorie restrictions or a sport program were incorporated. This makes it difficult to assess the influence of VLCKD in each separate case.

As a main achievement, the adherers of ketogenic diets consider the reduction of insulin dosage in a long-term period. Insulin in overweight patients does not only suppress lipolysis but also slows down fat absorbtion. Unfortunately, insulin makes it more effectively when the body weight is higher, which was reported by a research team from Basel University Clinic $(156,159)$. It was shown that glucose load in patients with body mass index $\geq 30 \mathrm{~kg} / \mathrm{m}^{2}$ increases the level of insulin more than when $\mathrm{BMI} \leq 25 \mathrm{~kg} / \mathrm{m}^{2}$. 
It was long known from multiple reseaches that insulin therapy is not regarded as an effective option for patients with T2D in a long-term perspective. It refers to the general mortality as well as to cardiovascular diseases. (160-162).

This was observed by german diabetologists 30 years ago in the long-term investigation in 1987 (163).

Therefore, treatment with insulin was often doubted. Especially in Germany this issue should be cleared since practically nowhere insulin is used as a mass therapy for T2D (146).

According to the publication of the Independent Research and Consulting Institute for Health Issues (IGES) in Berlin, an individual consumption in Germany is much higher, e.g. twice as much as in France (146). It is evident that the system that stil calculates carbohydrates in "bread" units may face difficulties during transition to KD.

Reduction of triglyceride level and increase in HDL is viewed as a positive effect but at the same time there was an increase in LDL cholesterol level (164). However it is not problematic since it is explained by the transformation of small low density participles into bigger lower density participles, which are considered to be significantly less atherogenic (165).

Hallberg and authors gives a clear picture of risk factors for cardiovascular diseases: higher LDL was associated with bigger participles. Besides, ApoB remained unchanged and levels of blood pressure and inflammation markers developed favourably (166).

It is unknown, whether reduction of carbohydrates in a ratio has a positive influence on nonalcoholic fatty liver disease (NAFLD). Although the results are controversial $(167,168,169)$, but the transcriptome analysis has recently showed that improved lipid metabolism in the liver may be traced even on the genetic level (170).

We have already mentioned complications caused by low carbohydrate diets.

There are such problems as apathy, decreased attention, nausea and vomiting, hyperlikemia, decreased appetite, constipation, kidney stones arising with a lower fiber intake dealt with the decreased intake of carbohydrates. $(57,171)$. It is important that the nutrition contains enough fiber, as, for example, in leafy green vegetables, for example. General objections are not in the least justified with tolerance of the diet by patients, who should considerably change their food preferences. Nevertheless to date, numerous formula diets have emerged with cooking recommendations as practical solutions.

Finally, the experience of using a strick KD in patients with epilepsy shows that in certain cases cooper deficiency associated with anemia was found (172).
There are also findings that ketosis may prolong effects of anesthetic gases $(173,34)$.

And not less important: at the beginning the patients report about drowsiness, dizziness, fatique, insomnia, light nauseas, constipation - all symptoms that were named "keto-flu" but they normally lessen (26). Important: patients can continue physical training despite of limitation of carbohydrates $(176,177)$.

Lately a number of articles in the field of Wellness and Lifestyle has appeared on salts of ketone bodies. Main attention is paid to sport and additional heath benefits for using ketonic diet or ketone bodies as preparations (178-180).

The use of additional ketone bodies seems to be a new and interesting development at the world market.

Growing general and scientific interest to KD has given way to development of new fields of applications. We have already reported that in addition to classic ways of weight reduction and increasing working capacity a posivite effect of $\mathrm{KD}$ on cancer and treatment of neurodegenerative diseases (dementia, Alzheimer's disease etc) has been widely debated (181). Ablitlty of ketone bodies to reduce appetite has been often mentioned as an advantage for use as a trend diet (182).

$\mathrm{KD}$, probably has a high market potential. To date, there is no data on market volume of preparations based on $\beta \mathrm{HB}$ and other co-products. Scientifically relevant monitoring of general values of vital functions such as levels of blood $(\beta \mathrm{HB}$, glucose) and concentrations of acetone in outbreathed air could be performed during KD $(183,184)$.

Eventually, it should be necessary to write a review on supplements of ketone bodies based on $\beta \mathrm{HB}$ salts that are available in Europe and USA, with a focuse on their benefits and risks. Such assessment, which could review the market situation, its evolution and the degree of existing "keto-tendency", has not been conducted yet.

In addition, dietary supplements based on the ketone body $\beta$-hydroxybutyrate are interesting development that should be used with caution in KD practice. The new development of the market and the related researches has provided a great deal of new information on ketone bodies. Anyway, $\beta \mathrm{HB}$ salts should not be used without control because we still do not have the full information on spread and severity of their side effects, for example, in relation to gastrointestinal symptoms. Particularly in a long-term perspective.

A general estimation of some advertisements, concerning the benefits for neurodegenerative diseases and weight reduction has shown the necessity of further researches in many fields. This would allow referring to possible $\beta \mathrm{HB}$ effects as evidence-based facts. 
There is substantial evidence of decreased appetite. That is why the use in combination with $\mathrm{KD}$ is considered as an interesting aspect that improves a daily diet. For instance, the limitation of daily amount of fat might considerably simplify and improve the situation on $\mathrm{KD}(154)$.

Not long ago such titles as "Earliar death due to low cab nutrition" shocked the adherers of low carb diets (185). In particular, there is a research of Harvard University team headed by cardiologist Prof. Dr. Scott D. Solomon (186). It was shown that diets with low and high contents of carbohydrates were linked with increase in mortality compared to moderate consumption of carbohydrates (about $50 \%$ of daily requirement in energy). This moderate option is associated with lowerest mortality level (Lancet Public Health 2018; 3 (9): e419-28).

Solomon team has analysed the data of 15428 Americans, who provided information on their ratio in 1987-1989. Then the respondents participated in the study on risk of atherosclerosis (ARIC). In the period from 1993 to 1995 the respondents were questioned again and the study was targeted on mortality level.

According to ARIC, "sweet spot" for carbohydrate intake comes to $50-55 \%$ of the total energy and associated with the lowest risk of death. Intake of carbohydrates $<30 \%$ is correlated with a higher level of mortality (Hazard Ratio [HR] 1,37; 95\%-confidence interval $[95-\%-C I] 1,16-1,63)$. The result was less manifested at a higher consumption of carbohydrates $>65$ (HR 1,16; 95-\%-KI 1,02-1,33).

Solomon and his colleagues has discovered this U-shaped connection between carbohydrates and mortality in metaanalyses of 7 further studies (carbohydrates < 40\%: HR 1,20 [1,09-1,32], carbohydrates > 70\%, HR 1 , $23[1,11-1,36])$.

In addition, when respondents consumed more animal fats and proteins the mortality was higher (HR $1,18,95 \%$ CI 1,08-1,29); when fats and proteins were of plant-based, the mortality level was lower. (HR 0,82 $[0,78-0,87])$.

Besides, a recent study of Polish researches presented at European Cardiological Conference reached a similar conclusion (187). And the press release of German Society of Cardiology warns of dangers of low carbohydrate diets. The cardiologists are supported by DGE experts (188).

On the other hand there has been a massiive methodological criticism of ARIC study.

Apart from carbohydrate intake, there is a question of the quality of nutrition in the group of the lowest carbohydrate intake. This issue has not been addressed. The critics see this as the weakest point. In 1980s and 1990s it was traditionally recommended to consume more products that rich in carbohydrates and low in fat. We may suggest that those who used the diet with low carbohydrates intake regardless the modern recommendations were not most healthy and disciplined people. Suggestively the "low level carbohydrate level", mentioned in the ARIC study had nothing to do with a modern conceipt of low carbohydrate intake. Fried chicken and hamburgers had been preferred to salmon and zucchini. Moreover, in the ARIC-study there was no data on alcohol consumption.

From the point of view of the opponents (185) none of these studies can provide evidence that a certain diet may cause long-term effect on mortality - either a positive or a negative one. To perform these prospective randomized controlled studies are necessary, but unfortunately, they are hardly conductable, in the first line because of ethical reasons.

Animal studies and short intervention researches of a controlled diet showed that diets with low carbohydrate content were favorable in terms of longevity or at least positevely influenced risks factors for cardiovascular diseases (185).

The opponents of the study consider that the current analysis has no scientific evidence to claim that low carbohydrate diet could shorten life expectancy. At least there is nothing adverse if doctors continue to recommend their overweight patients to use a mediterenean diet with low content of carbohydrates according to Prof. Matthias Blüher, Head of Clinic of Endocrinology and Nephrology for Overweight Adults, at Leipzig University (185). So far, however, the disagreement among specialists has not been resolved and the subject should be further explored.

24 experts from U.S. News Diet Ranking placed Atkins diet, Eco-Atkins and ketogenic diet in the categories "the best diet in general", "loss of weight" and "quick loss of weight". The best note was given to Atkins diet. In the category of quick loss of weight the ketogenic diet took $13^{\text {th }}$ place, anyway KD only occupied $39^{\text {th }}$ place in the general ranking of diets (139, 154, 189-191).

The DGE opinion in regard of KD and other unbalanced diets remains practically the same: any diet with a big amount of nutricients, either fat or carbohydrate or protein limits the choice of foods.

In this case the body is inadequately supplied with essential micronutrients, such as vitamins, minerals and fibers or, too much calories or saturated fatty acids are released. The oneside diet in long term has negative effects on health. Thus, the results of ARIC study (188) show that a shortened life expectancy due to inbalanced diets is not suprising.

Foods with high content of fiber, such as whole grains, legumes, vegetables and fruits should be eaten 
without restriction, simple carbohydrates, such as mono- and disaccharides as added sugar and purified starch - only in small amounts. It is important to improve the quality of fats and carbohydrates in our western diet, as well as to avoid too high consumption of energy. This was stated by DGE in its PURE-Study (192) published in Lancet in 2018.

A well balanced, wholesame and plant-based diet formulated in 10 guidelines by DGE maintains good health, which is also confirmed by ARIC-Study (188).

\section{CONCLUSIONS}

Recent studies of ketonic diets (KD) for treatment of neurologlical, oncological diseases and diseases of the metabolic syndrome were reviewed.

Based on the literary sources a conclusion on unacceptability of using ketogenic diets in cancer patients was drawn. This was also stated by German Cancer Gesellscaft. German Nutrition Society and other researches consider it irrational to use KD for reduction of weight referring to ARIC-study, which associates carbohydrate depletion with a shorted life expectancy and possible complications.

Nevertheless, there is no doubt that the use of different ketogenic diets $(\mathrm{KD})$ for treatment of epilepsy and certain metabolic deficiencies (GLUT1 deficiency and pyruvate dehydrogenase deficiency (PDHD)) remains feasible and effective.

\section{REFERENCES}

1. Wilder RM (1921) The effects of ketonuria on the course of epilepsy. Bull Mayo Clin 2: 307

2. Vanitallie TB, Nufert TH (2003) Ketones. Metabolism's ugly duckling. Nutr Rev 61: 327-341

3. A. Dressler, P. Trimmel-SChWAHOFER, M. Feucht, E. Haberlandt, E. Trinka, C. Baumgartner, J. Dobesberger, M. Feichtinger, M. Graf, C. Rauscher, E. Pataraia, F. Zimprich, G. LUEF, I. UNTERBERGER, K. SCHLACHTER Ketogene Diäten vom Säugling bis zum Erwachsenen: Formen, Umsetzung und Nebenwirkungen

4. Zамміт VA (1984) Mechanisms of regulation of the partition of fatty acids between oxidation and esterification in the liver. Prof Lipid Res 23: 39-67

5. Mitchell Ga, Kassovska-Bratinova S, BouKAFTANE Y ET AL. (1995) Medical aspects of ketone body metabolism. Clin Invest Med 18: 193-216

6. Cahill GF (1970) Starvation in man. N Engl J Med 282: 668-675

7. Koeslag JH, Noakes TD, Sloan AW (1980) Postexercise ketosis. J Physiol 301: 79-90

8. Wilder RM, Winter MD (1922) The thresh old of ketogenesis. J Biol Chem 52: 393-401

9. Cahill GF (2006) Fuel metabolism in starvation. Annu Rev Nutr 26: 1-22
10. Schoeler NE, Cross JH (2016) Ketogenic dietary therapies in adults with epilepsy: a practical guide. Pract Neurol 16: 208-214

11. Bier DM, Brosnan JT, Flatt JP et al. (1999) Report of the IDECG working group on lower and upper limits of carbohydrate and fat intake. International Dietary Energy Consultative Group. Eur J Clin Nutr 53(Suppl 1): S177-S178

12. Ye F, Li X, Jiang W ET AL. (2015) Efficacy of and patient compliance with a ketogenic diet in adults with intractable epilepsy. A meta-analysis. J Clin Neurol 11: 26-31

13. Payne Ne, Cross JH, Sander JW et al. (2011) The ketogenic and related diets in adolescents and adults--a review. Epilepsia 52: 1941-1948

14. Tobias Fischer, Thorsten MarguardT Dietary supplements based on the ketone body $\beta$-hydroxybutyrate Market analysis and evaluation of ingredients of supplements used in the USA Ernaehrungs Umschau international | 12/2018»

15. Owen, O.E.; Morgan, A.P.; Kemp, H.G.; Sullivan, J.M.; Herrera, M.G.; Cahill, G.F., JR. Brain metabolism during fasting. J. Clin. Investig. 1967, 46, 1589-1595.

16. Youm, Y.H.; NGuYen, K.Y.; GRANT, R.W.; GoldBERG, E.L.; BODOgaI, M.; KIM, D.; D’Agostino, D.; Planavsky, N.; Lupfer, C.; Kanneganti, T.D.; ET AL. The ketone metabolite beta-hydroxybutyrate blocks NLRP3 inflammasome-mediated inflammatory disease. Nat. Med. 2015, 21, 263-269.

17. IJfF, D.M.; Postulart, D.; Lambrechts, D.; Majoie, M.; DE Kinderen, R.J.A.; Hendriksen, J.G.M.; Evers, S.; Aldenkamp, A.P. Cognitive and behavioral impact of the ketogenic diet in children and adolescents with refractory epilepsy: A randomized controlled trial. Epilepsy Behav 2016, 60, 153-157.

18. Kashiwaya, Y.; Bergman, C.; Lee, J.H.; Wan, R.; King, M.T.; Mughal, M.R.; OKun, E.; Clarke, K.; Mattson, M.P.; Veech, R.L. A ketone ester diet exhibits anxiolytic and cognition-sparing properties, and lessens amyloid and tau pathologies in a mouse model of Alzheimer's disease. Neurobiol. Aging 2013, $34,1530-1539$.

19. Kim, D.Y.; Davis, L.M.; Sullivan, P.G.; MaALouf, M.; Simeone, T.A.; van Brederode, J.; RHo, J.M. Ketone bodies are protective against oxidative stress in neocortical neurons. J. Neurochem. 2007, 101, 1316-1326.

20. Cox, P.J.; Kirk, T.; Ashmore, T.; Willerton, K.; Evans, R.; Smith, A.; Murray, A.J.; Stubbs, B.; WEST, J.; MCLURE, S.W.; ET AL. Nutritional Ketosis Alters Fuel Preference and Thereby Endurance Performance in Athletes. Cell Metab. 2016, 24, 256-268.

21. Sato, K.; Kashiwaya, Y.; Keon, C.A.; Tsuchiya, N.; KIng, M.T.; Radda, G.K.; Chance, B.; Clarke, K.; Veech, R.L. Insulin, ketone bodies, and mitochondrial energy transduction. FASEB J. Off. Publ. Fed. Am. Soc. Exp. Biol. 1995, 9, 651-658. 
22. Brian A. Parker, Chase M. Walton, Sheryl T. Carr, Jacob L. Andrus, Eric C. K. Cheung, Michael J. Duplisea, Esther K. Wilson, Carrie Draney, Daniel R. Lathen, Kyle B. KenNer, DAVID M. ThOMSON, JeFFERY S. TESSEM AND BENJAMIN T. BIKMAN, $\beta$-Hydroxybutyrate Elicits Favorable Mitochondrial Changes in Skeletal Muscle International Journal of Molecular Sciences https:// www.mdpi.com/1422-0067/19/8/2247/htm

23. Langhans W, Wiesenreiter F, Scharrer E (1983) Different effects of subcutaneous D,Lc-3hydroxybutyrate and acetoacetate injections on food intake in rats. Physiol Behav 31: 483-486

24. Féry F, Balasse EO (1988) Effect of exercise on the disposal of infused ketone bodies in humans. J Clin Endocrinol Metab 67: 245-250

25. van Hove JLK, Grünewald $S$, Jaeken J et al. (2003) D,L-3-hydroxybutyrate treatment of multiple acyl-CoA dehydrogenase deficiency (MADD). Lancet 361: 1433-1435

26. Habarou F, Bahi-Buisson N, Lebigot E ET AL. (2017) Ketone bodies as a possible adjuvant to ketogenic diet in PDHc deficiency but not in GLUT1 deficiency. JIMD reports 38: 53-59

27. Plecko B, Stoeckler-Ipsiroglu S, Schober E ET AL. (2002) Oral beta-hydroxybutyrate supplementation in two patients with hyperinsulinemic hypoglycemia: monitoring of beta-hydroxybutyrate levels in blood and cerebrospinal fluid, and in the brain by in vivo magnetic resonance spectroscopy. Pediatr Res 52: 301-306

28. J. S. Volek and S. D. Phinney, The Art and Science of Low Carbohydrate Living, Beyond Obesity, LLC, Miami, FL, USA, 2011.

29. J. S. Volek and S. D. Phinney, The Art and Science of Low Carbohydrate Performance, Beyond Obesity, LLC, Miami, FL, USA, 2012.

30. Vincent J. Miller, Frederick A. Villamena, AND JefF S. Volek Nutritional Ketosis and Mitohormesis: Potential Implications for Mitochondrial Function and Human Health Journal of Nutrition and Metabolism Volume 2018, Article ID 5157645, 27 pages https://doi.org/10.1155/2018/5157645

31. Paoli A. Ketogenic diet for obesity: friend or foe? International Journal of Environmental Research and Public Health. 2014;11(2):2092-2107. doi: 10.3390/ ijerph1 10202092. [PMC free article] [PubMed] [CrossRef] [Google Scholar]

32. Bueno N. B., de Melo I. S., de Oliveira S. L., da Rocha AtaIDE T. Very-low-carbohydrate ketogenic diet v. low-fat diet for long-term weight loss: a metaanalysis of randomised controlled trials. British Journal of Nutrition. 2013;110(7):1178-1187. doi: 10.1017/ s0007114513000548.

33. McKenzie A. L., Hallberg S. J., Creighton B. C., ET AL. A novel intervention including individualized nutritional recommendations reduces hemoglobin Alc level, medication use, and weight in type 2 diabetes. JMIR Diabetes. 2017;2(1):p. 14. doi: 10.2196/diabetes.6981.

34. Feinman R. D., Volek J. S. Carbohydrate restriction as the default treatment for type 2 diabetes and metabolic syndrome. Scandinavian Cardiovascular Journal. 2008;42(4):256-263. doi: $10.1080 / 14017430802014838$.

35. Feinman R. D., Pogozelski W. K., Astrup A., ET AL. Dietary carbohydrate restriction as the first approach in diabetes management: critical review and evidence base. Nutrition. 2015;31(1):1-13. doi: 10.1016/j.nut.2014.06.011.

36. Paoli A., Rubini A., Volek J. S., Grimaldi K. A. Beyond weight loss: a review of the therapeutic uses of very-low-carbohydrate (ketogenic) diets. European Journal of Clinical Nutrition. 2013;67(8):789-796. doi: 10.1038/ejen.2013.116.

37. Cotter D. G., Schugar R. C., Crawford P. A. Ketone body metabolism and cardiovascular disease. American Journal of Physiology-Heart and Circulatory Physiology. 2013;304(8):H1060-H1076. doi: 10.1152/ajpheart.00646.2012.

38. Kosinski C., Jornayvaz F. R. Effects of ketogenic diets on cardiovascular risk factors: evidence from animal and human studies. Nutrients. 2017;9(5) doi: $10.3390 / \mathrm{nu} 9050517$.

39. Hyde P. N., Lustberg M. B., Miller V. J., LaFountain R. A., Volek J. S. Pleiotropic effects of nutritional ketosis: conceptual framework for ketoadaptation as a breast cancer therapy. Cancer Treatment and Research Communications. 2017;12(2017):3239. doi: 10.1016/j.ctarc.2017.06.001.

40. Branco A. F., Ferreira A., Simoes R. F., ET AL. Ketogenic diets: from cancer to mitochondrial diseases and beyond. European Journal of Clinical Investigation. 2016;46(3):285-298. doi: 10.1111/ eci. 12591 .

41. Stafstrom C. E., Rho J. M. The ketogenic diet as a treatment paradigm for diverse neurological disorders. Frontiers in Pharmacology. 2012;3:p. 59. doi: 10.3389/ fphar.2012.00059.

42. Oliveira C. L., Mattingly S., Schirrmacher R., Sawyer M. B., Fine E. J., Prado C. M. A Nutritional perspective of ketogenic diet in cancer: a narrative review. Journal of the Academy of Nutrition and Dietetics. 2017 doi: 10.1016/j.jand.2017.02.003. in press.

43. Simone B. A., Champ C. E., Rosenberg A. L., et AL. Selectively starving cancer cells through dietary manipulation: methods and clinical implications. Future Oncology. 2013;9(7):959-976. doi: 10.2217/ fon.13.31

44. Seyfried T. N., Marsh J., Shelton L. M., Huysentruyt L. C., Mukherjee P. Is the restricted ketogenic diet a viable alternative to the standard of care for managing malignant brain cancer? Epilepsy Research. 2012;100(3):310-326. doi: 10.1016/j.eplepsyres.2011.06.017. 
45. Fine E. J., Feinman R. D. Insulin, carbohydrate restriction, metabolic syndrome and cancer. Expert Review of Endocrinology \& Metabolism. 2014;10(1):15-24. doi: $10.1586 / 17446651.2014 .960392$.

46. Allen B. G., Bhatia S. K., Anderson C. M., et AL. Ketogenic diets as an adjuvant cancer therapy: history and potential mechanism. Redox Biology. 2014;2:963-970. doi: 10.1016/j.redox.2014.08.002

47. Vidali S., Aminzadeh S., Lambert B., et al. Mitochondria: the ketogenic diet-a metabolism-based therapy. International Journal of Biochemistry \& Cell Biology. 2015;63:55-59. doi: 10.1016/j.biocel.2015.01.022.

48. Hartman A. L. Neuroprotection in metabolismbased therapy. Epilepsy Research. 2012;100(3):286294. doi: 10.1016/j.eplepsyres.2011.04.016.

49. Gasior M., Rogawski M. A., Hartman A. L. Neuroprotective and disease-modifying effects of the ketogenic diet. Behavioural Pharmacology. 2006;17(56):431-439. doi: 10.1097/00008877-20060900000009 .

50. Maalouf M., Rho J. M., Mattson M. P. The neuroprotective properties of calorie restriction, the ketogenic diet, and ketone bodies. Brain Research Reviews. 2009;59(2):293-315. doi: 10.1016/j.brainresrev.2008.09.002.

51. Paoli A., Bianco A., Damiani E., Bosco G. Ketogenic diet in neuromuscular and neurodegenerative diseases. BioMed Research International. 2014;2014:10. doi: 10.1155/2014/474296.474296

52. Moreno C. L., Mobbs C. V. Epigenetic mechanisms underlying lifespan and age-related effects of dietary restriction and the ketogenic diet. Molecular and Cellular Endocrinology. 2017;455:33-40. doi: 10.1016/j. mce.2016.11.013.

53. Edwards C., Copes N., Bradshaw P. C. D- $\beta$ hydroxybutyrate: an anti-aging ketone body. Oncotarget. 2015;6(6):3477-3478. doi: 10.18632/oncotarget. 3423 .

54. Veech R. L., Bradshaw P. C., Clarke K., CurTis W., Pawlosky R., King M. T. Ketone bodies mimic the life span extending properties of caloric restriction. IUBMB Life. 2017;69(5):305-314. doi: 10.1002/iub.1627.

55. Roberts M. N., Wallace M. A., Tomilov A. A., ET AL. A ketogenic diet extends longevity and healthspan in adult mice. Cell Metabolism. 2017;26(3):539 e535-546 e535. doi: 10.1016/j.cmet.2017.08.005. [PMC free article] [PubMed] [CrossRef] [Google Scholar]

56. Newman J. C., Covarrubias A. J., Zhao M., ET AL. Ketogenic diet reduces midlife mortality and improves memory in aging mice. Cell Metabolism. 2017;26(3):547 e548-557 e548. doi: 10.1016/j. cmet.2017.08.004.

57. Ulrike Och, Tobias Fischer, Thorsten MarQUARDT. Ernährungs Umschau | 8/2017 Ketogene
Diät - eine Herausforderung für Patienten und Fachkräfte DOI: 10.4455/eu.2017.031

58. Vanitallie TB, Nufert TH (2003) Ketones. Metabolism's ugly duckling. Nutr Rev 61: 327-341

59. LAFFEL L (1999) Ketone bodies: a review of physiology, pathophysiology and application of monitoring to diabetes. Diabetes Metab Res Rev 15: 412-426

60. Cahill GF (2006) Fuel metabolism in star vation. Annu Rev Nutr 26: 1-22

61. Laeger T, Metges CC, Kuhla B (2010) Role of beta-hydroxybutyric acid in the central regulation of energy balance. Appetite 54: 450-455

62. Paoli A, Rubini A, Volek JS et al. (2013) Be yond weight loss: a review of the therapeutic uses of verylow-carbohydrate (ketogenic) diets. Eur J Clin Nutr 67: 789-796

63. LAFFEL L (1999) Ketone bodies: a review of physiology, pathophysiology and application of monitoring to diabetes. Diabetes Metab Res Rev 15: 412-426

64. Cahill GF, Veech RL (2003) Ketoacids? Good medicine? Trans Am Clin Climatol Assoc 114: $149-163$

65. Bier DM, Brosnan JT, Flatt JP et al. (1999) Report of the IDECG Working Group on lower and upper limits of carbohydrate and fat intake. International Dietary Energy Consultative Group. Eur J Clin Nutr 53 Suppl 1: S177-S178

66. Newman JC, Verdin E (2014) beta-hydroxybutyrate: much more than a metabolite. Diabetes Res Clin Pract 106: 173-181

67. AWMF (2014) Ketogene Diäten. S1-Leitlinie 022/021. Leitlinien der Gesellschaft für Neuropädiatrie: $1-21$

68. KLePper J, Leiendecker B (2011) Ketogene Diät bei refraktärer Epilepsie im Kindesalter. Monatsschr Kinderheilkd 159: 739-744

69. Schoeler NE, Cross JH (2016) Ketogenic dietary therapies in adults with epilepsy: a practical guide. Practical Neurology 16: 208-214

70. Simeone TA, Simeone KA, Rho JM (2017) Ketone bodies as anti-seizure agents. Neurochemical Res (DOI: $10.1007 /$ s1 1064-017-2253-5)

71. Chang P, Augustin K, Boddum Ket al. (2016) Seizure control by decanoic acid through direct AMPA receptor inhibition. Brain 139: 431-443

72. Hughes SD, Kanabus M, Anderson G et al. (2014) The ketogenic diet component decanoic acid increases mitochondrial citrate synthase and complex I activity in neuronal cells. J Neurochem 129: 426-433

73. Levy RG, Cooper PN, Giri P (2012) Ketogenic diet and other dietary treatments for epilepsy. Cochrane Database Syst Rev 3: CD001903

74. Payne Ne, Cross JH, Sander JW et al. (2011) The ketogenic and related diets in adolescents and adults - a review. Epilepsia 52: 1941-1948 
75. Vivo DC DE, TrifiletTI RR, JACOBSON RI ET AL. (1991) Defective glucose transport across the bloodbrain barrier as a cause of persistent hypoglycorrhachia, seizures, and developmental delay. N Engl J Med 325: 703-709

76. Scholl-Burgi S, Holler A, Pichler K et al. (2015) Ketogenic diets in patients with inherited metabolic disorders. J Inherit Metab Dis 38: 765-773

77. KLEPPER J, LEIENDECKer B (2013) Glut1 deficiency syndrome and novel ketogenic diets. J Child Neurol 28: $1045-1048$

78. Sofou K, Dahlin M, Hallbook T et al. (2017) Ketogenic diet in pyruvate dehydrogenase complex deficiency: short- and long-term outcomes. J Inherit Metab Dis 40: 237-245

79. KLEPPER, J., 2008. Glucose transporter deficiency syndrome (GLUT1DS) and the ketogenic diet. Epilepsia 49 (Suppl 8), 46-49.

80. KLePper J, LeIENDECKer B (2011) Ketogene Diät bei refraktärer Epilepsie im Kindesalter. Monatsschr Kinderheilkd 159: 739-744

81. Schoeler NE, Cross JH (2016) Ketogenic dietary therapies in adults with epilepsy: a practical guide. Practical Neurology 16: 208-214

82. Christin Cerniuc, Tobias Fischer, Anna BaUMEISTER, URSULA BORDEWICK-DELL Ernaehrungs Einfluss des intermittierenden Fastens (5:2) auf die Ketonkörperproduktion von gesunden Probandinnen Umschau international | 1/2019 DOI: $10.4455 /$ eu. 2019.002

83. Atrins RC. Dr. Atkins diet revolution. The high calorie way to stay thin forever. D McKay Co, Philadelphia (1972)

84. Kossoff EH, Cervenka MC, Henry BJ et al. (2013) A decade of the modified Atkins diet (20032013): results, insights, and future directions. Epilepsy Behav B 29: 437-442

85. Kossoff EH, McGrogan JR, Bluml RM et al. (2006) A modified Atkins diet is effective for the treatment of intractable pediatric epilepsy. Epilepsia 47: $421-424$

86. Aoyama T, Nosaka N, Kasai M (2007) Research on the nutritional characteristics of medium-chain fatty acids. JMI 54: 385-388

87. Huttenlocher PR, Wilbourn AJ, Signore JM (1971) Medium-chain triglycerides as a therapy for intractable childhood epilepsy. Neurology 21: $1097-1103$

88. Marten B, Pfeuffer M, Schrezenmeir J (2006) Medium-chain triglycerides. Int Dairy J 16: $1374-$ 1382

89. Verordnung (EU) Nr. 1169/2011 des Europäischen Parlaments und des Rates vom 25. Oktober 2011

90. Neal EG, Chaffe H, Schwartz RH et al. (2009) A randomized trial of classical and mediumchain triglyceride ketogenic diets in the treatment of childhood epilepsy. Epilepsia 50: 1109-1117
91. LIU YC, WANG H (2013) Medium-chain triglyceride ketogenic diet, an effective treatment for drug-resistant epilepsy and a comparison with other ketogenic diets. BMJ 36: 9-15

92. MCT oil diet. URL: www.charliefoundation. org/ explore-ketogenic-diet/explore-2/mctoil-diet Zugriff 18.05.17

93. Jenkins DJ, Wolever TM, TAYlor RH ET AL. (1981) Glycemic index of foods: a physiological basis for carbohydrate exchange.

94. STroнm D (2013) Glykämischer Index und glykämische Last - ein für die Ernährungspraxis des Gesunden relevantes Konzept? Wissenschaftliche Stellungnahme der DGE. Ernährungs Umschau 60(1): M26-M38

95. Pfeifer HH, Thiele EA (2005) Low-glycemicindex treatment: a liberalized ketogenic diet for treatment of intractable epilepsy. Neurology 65: $1810-1812$

96. Anton SD, Moehl K, Donahoo WT et al. (2017) Flipping the metabolic switch. Understanding and applying the health benefits of fasting. Obesity [published online: 31.10.2017; DOI: 10.1002/ oby.22065]

97. Maughan RJ, Fallah J, Coyle EF (2010) The effects of fasting on metabolism and performance. Br J Sports Med 44: 490-494

98. 12. Mosley M, Spencer M. The fast fiet. Lose weight, stay healthy, live longer. Short Books, New York (2014)

99. Varady K, Gottlieb B. The every other day diet. The only fasting diet proven by science. Hyperion, New York (2014)

100.Harvie M, Howell PT. The 2-day diet. Diet two days a week. eat the mediterranean way for five. Harmony Books, New York (2013)

101.15. Cahill GF (2006) Fuel metabolism in starvation. Annu Rev Nutr 26: 1-22

102.16. Fukao T, Lopaschuk GD, Mitchell GA (2004) Pathways and control of ketone body metabolism. On the fringe of lipid biochemistry. Prostaglandins, leukotrienes, and essential fatty acids 70: 243-251

103.17. Newman JC, Verdin E (2017) $\beta$-Hydroxybutyrate. A signaling metabolite. Annu Rev Nutr 37: 51-76

104. Cahill GF, Veech RL et al. (2003). Ketoacids? Good medicine? Trans Am Clin Climatol Assoc 114: $149-163$

105. Varady Ka, Bhutani S, Church EC et al. (2009) Short-term modified alternate-day fasting: a novel dietary strategy for weight loss and cardioprotection in obese adults. Am J Clin Nutr 90: 1138-1143

106. VARADY KA (2011) Intermittent versus daily calorie restriction: which diet regimen is more effective for weight loss? Obes Rev 12: e593-e601 
107.Harvie MN, Pegington M, Mattson MP et AL. (2011) The effects of intermittent or continuous energy restriction on weight loss and metabolic disease risk markers: a randomized trial in young overweight women. Int J Obes (2005) 35: 714-727

108. Harvie M, Wright C, Pegington M et al. (2013) The effect of intermittent energy and carbohydrate restriction $v$. daily energy restriction on weight loss and metabolic disease risk markers in overweight women. Br J Nutr 110: 1534-1547

109. Klempel MC, Kroeger CM, Varady KA (2013) Alternate day fasting (ADF) with a high-fat diet produces similar weight loss and cardio-protection as ADF with a low-fat diet. Metab Clin Exp 62: 137-143

110.BARNOSKY AR, HODDY KK, UNTERMAN TG ET AL. (2014) Intermittent fasting vs daily calorie restriction for type 2 diabetes prevention: a review of human findings. Transl Res 164: 302-311

111. Rothschild J, Hoddy KK, Jambazian P ET AL. (2014) Time-restricted feeding and risk of metabolic disease. A review of human and animal studies. Nutr Rev 72: 308-318

112. Headland M, Clifton PM, Carter S et al. (2016) Weight-loss outcomes. A systematic review and meta-analysis of intermittent energy restriction trials lasting a min

113. Hall SE, Wastney ME, Bolton TM et al. (1984) Ketone body kinetics in humans: the effects of insulin-dependent diabetes, obesity, and starvation. J Lipid Res 25: 1184-1194

114.Johnson RE, Sargent F, Passmore R (1958) Normal variations in total ketone bodies in serum and urine of healthy young men. QJ Exp Physiol Cogn Med Sci 43: 339-344

115. Christin Cerniuc+, Tobias Fischer+, AnNa BAumeister, Ursula BordeWICK-DEll Einfluss des intermittierenden Fastens (5:2) auf die Ketonkörperproduktion von gesunden Probandinnen Ernaehrungs Umschau international | 1/2019 DOI: $10.4455 /$ eu.2019.002

116.SChübel R, Nattenmüller J, SoOkThai D ET AL. (2018) Effects of intermittent and continuous calorie restriction on body weight and metabolism over one year: a randomized controlled trial. AJCN 108: 933-945

117.Headland ML, Clifton PM, Keogh JB (2018) Effect of intermittent compared to continuous energy restriction on weight loss and weight maintenance after 12 months in healthy overweight or obese adults. Int J Obes, published online 23. November 2018. DOI: $10.1038 / s 41366-018-0247-2$

118.Sundfør TM, Svendsen M, Tonstad S (2018) Effect of intermittent versus continuous energy restriction on weight loss, maintenance and cardiometabolic risk: a randomized 1-year trial. Nutr Metab Cardiovasc Dis 28: 698-706

119.Peterman MG (1925) The ketogenic diet in epilepsy. JAMA 84: 1979
120.BAUMEISTER FAM. Ketogene Diät. Ernährung als Therapiestrategie bei Epilepsien und anderen Erkrankungen. Schattauer, Stuttgart (2012)

121. Deutsche Gesellschaft für Ernährung e. V. DGE-Position. Richtwerte für die Energiezufuhr aus Kohlenhydraten und Fett. Bonn, Deutsche Gesellschaft für Ernährung (2011)

122.Lin A, Turner Z, Doerrer SC et al. (2017) Complications during ketogenic diet initiation: prevalence, treatment, and influence on seizure outcomes. Pediatr Neurol 68: 35-39

123. McClernon FJ, Yancy WS, Eberstein JA et al. (2007) The effects of a low-carbohydrate ketogenic diet and a low-fat diet on mood, hunger, and other self-reported symptoms. Obesity 15: 182-187

124.Johnstone AM, Horgan GW, Murison SD ET AL. (2008) Effects of a high-protein ketogenic diet on hunger, appetite, and weight loss in obese men feeding ad libitum. Am J Clin Nutr 87: 44-55

125.Dashti HM, Al-Zaid NS, Mathew TC et al. (2006) Long term effects of ketogenic diet in obese subjects with high cholesterol level. Mol Cell Biochem 286: $1-9$

126. Dashti HM, Mathew TC, Hussein T et al. (2004) Long-term effects of a ketogenic diet inobese patients. Exp Clin Cardiol 9: 200-205

127.BAnKa S, Goede C de, Yue WW et AL. (2014) Expanding the clinical and molecular spectrum of thiamine pyrophosphokinase deficiency: a treatable neurological disorder caused by TPK1 mutations. Mol Genet Metab 113: 301-306

128. Vander Heiden MG, Cantley LC, Thompson CB (2009) Understanding the Warburg effect: the metabolic requirements of cell proliferation. Science 324: 1029-1033

129.Schroeder U, Himpe B, Pries R et AL. (2013) Decline of lactate in tumor tissue after ketogenic diet: in vivo microdialysis study in patients with head and neck cancer. Nutr Cancer 65: 843-849

130.Bensinger SJ, Christofk HR (2012) New aspects of the Warburg effect in cancer cell biology. Semin Cell Dev Biol 23: 352-361

131. Stellungnahme zu ketogenen und kohlenhydratarmen Diäten bei Menschen mit Krebs Nicole Erickson, Daniel Buchholz, Jutta Hübner für die Arbeitsgemeinschaft Prävention und Integrative Onkologie (PRIO) der Deutschen Krebsgesellschaft (DKG)

132.Erickson N, Boscheri A, Linke B, Huebner J (2017) Systematic review: isocaloric ketogenic dietary regimes for cancer patients. Med Oncol 34: 72

133. Gesellschaft für Neuropädiatrie. S1-Leitline 022/21: Ketogene Diäten. AWMF Online Register (2014)

134. Kossoff EH, Hartman AL (2012) Ketogenic diets: new advances for metabolism-based therapies. Curr Opin Neurol 25: 173-178 
135. Pfeifer HH, LyCzKowski DA, Thiele EA (2008) Low glycemic index treatment: implementation and new insights into efficacy. Epilepsia 49 (Suppl 8): $42-45$

136. Fine EJ, Segal-Isaacson CJ, Feinman RD et AL. (2012) Targeting insulin inhibition as a metabolic therapy in advanced cancer: a pilot safety and feasibility dietary trial in 10 patients. Nutrition 28: 1028-1035

137. Tan-Shalaby JL, Carrick J, Edinger K et al. (2016) Modified Atkins diet in advanced malignancies - final results of a safety and feasibility trial within the Veterans Affairs Pittsburgh Healthcare System. Nutr Metab (Lond) 13: 52

138.Urbain P, Strom L, Morawski L et al. (2017) Impact of a 6-week non-energy-restricted ketogenic diet on physical fitness, body composition and biochemical parameters in healthy adults. Nutr Metab (Lond) 14: 17

139.U.S. News. Best weight-loss diets. URL: https:// health.usnews.com/best-diet/bestweight-loss-diets Zugriff 21.02.18

140. OCH U, Fischer T, MarquardT T (2017). Ketogene Diät - eine Herausforderung für Patienten und Fachkräfte. Einsatz, Wirkungsweise und Durchführung bei Epilepsien im Kindesalter und seltenen angeborenen Stoffwechselerkrankungen. Ernährungs Umschau 64: M444-M457

141.Scholl-Burgi S, Holler A, Pichler K et al. (2015). Ketogenic diets in patients with inherited metabolic disorders. J Inherit Metab Dis 38: 765-773

142.Effectiveness and Safety of a Novel Care Model for the Management of Type 2 Diabetes at 1 Year: An Open-Label, Non-Randomized, Controlled Study https://link.springer.com/article/10.1007\%2 Fs13300-018-0373-9

143. Bravata DM, Sanders L, Huang J et al. (2003). Efficacy and safety of low-carbohydrate diets. A systematic review. JAMA 289: 1837-1850

144. Bueno NB, Melo ISV de, Oliveira SL de et al. (2013). Very-low-carbohydrate ketogenic diet v. lowfat diet for long-term weight loss. A meta-analysis of randomised controlled trials. Br J Nutr 110: 11781187

145. Gibson AA, Seimon RV, LeE CMY et Al. (2015). Do ketogenic diets really suppress appetite? A systematic review and meta-analysis. Obes Rev 16: 64-76

146. Gegen Diabetes und Adipositas: Dein Freund, der Ketonkörper Dtsch Arztebl 2018; 115(41): A-1810 / B-1524 / C-1510 Lenzen-Schulte, Martina

147.HAllberg SJ: ,Reversing type 2 diabetes starts with ignoring the guidelines': education from Dr Sarah Hallberg's TEDx talk. Br J Sports Med 2018; 52 (13): 869-71 CrossRef MEDLINE

148. NANNINEN AH: Metabolic effects of the very-lowcarbohydrate diets: misunderstood "villains" of human metabolism. J Int Soc Sports Nutr 2004; 1 (2): 7-11 CrossRefMEDLINE PubMed Central
149. LANGHANS W, Wiesenreiter F, SCHARRER E (1983) Different effects of subcutaneous D, L-3hydroxybutyrate and acetoacetate injections on food intake in rats. Physiol Behav 31: 483-486

150. Féry F, Balasse EO (1988) Effect of exercise on the disposal of infused ketone bodies in humans. J Clin Endocrinol Metab 67: 245-250

151.van Hove JLK, Grünewald S, Jaeken J ET aL. (2003) D, L-3-hydroxybutyrate treatment of multiple acyl-CoA dehydrogenase deficiency (MADD). Lancet 361: 1433-1435

152. Habarou F, BaHi-Buisson N, Lebigot E ET AL. (2017) Ketone bodies as a possible adjuvant to ketogenic diet in PDHc deficiency but not in GLUT1 deficiency. JIMD reports 38: 53-59

153.Plecko B, Stoeckler-Ipsiroglu S, Schober E ET AL. (2002) Oral beta-hydroxybutyrate supplementation in two patients with hyperinsulinemic hypoglycemia: monitoring of beta-hydroxybutyrate levels in blood and cerebrospinal fluid, and in the brain by in vivo magnetic resonance spectroscopy. Pediatr Res 52: $301-306$

154.Fischer T., Marquardt T. Diätetische Supplemente auf Basis des Ketonkörpers $\beta$-Hydroxybutyrat Marktanalyse und Bewertung der Inhaltsstoffe von Supplementen in den USA Ernaehrungs Umschau international 12/2018, 204-212, DOI: $10.4455 /$ eu. 2018.048

155. Hallberg SJ, McKenzie AL, Williams PT, et AL.: Effectiveness and Safety of a Novel Care Model for the Management of Type 2 Diabetes at 1 Year: An Open-Label, Non-Randomized, Controlled Study. Diabetes Ther 2018; 9 (2): 583-612. https://doi. org/10.1007/s13300-018-0373-9

156.Kempf K, Röhling M, STichert M, ET AL.: Telemedical Coaching Improves Long-Term Weight Loss in Overweight Persons: A Randomized Controlled Trial. Hindawi International Journal of Telemedicine and Applications 2018; Article ID 7530602. https:/ / doi.org/ 10.1155/2018/7530602

157. Feinmann RD, Pogozelski WK, Astrup A, et AL.: Dietary Carbohydrate restriction as the first approach in diabetes management: Critical Review and evidence base. Nutrition 2015; 31: 1-13

158. Gershuni VM, Yan SL, Medici V: Nutritional Ketosis for Weight Management and Reversal of Metabolic Syndrome. Current Nutrition Reports 2018; 7 : 97-106 https://doi.org/10.1007/s13668-018-0235-0

159.Meyer-Gerspach AC, Cajacob L, Riva D, eT AL.: Mechanisms Regulating Insulin Response to Intragastric Glucose in Lean and Non-Diabetic Obese Subjects: A Randomized, Double-Blind, ParallelGroup Trial. PLoS ONE 2016; 11 (3): https://doi. org/10.1371/journal.pone.0150803

160.NySTRöM T, Bodegard J, NATHANSON D, ET AL.: Second line initiation of insulin compared with DPP-4 inhibitors after metformin monotherapy is associated with increased risk of all-cause mortality, cardiovascular events, and severe hypoglycemia. Diabetes Res Clin 
Pract 2017; 123: 199-208 https://doi.org/10.1016/j. diabres.2016.12.004

161.Ekström N, Svensson AM, Miftaraj M, ET AL.: Cardiovascular safety of glucose-lowering agents as add-on medication to metformin treatment in type 2 diabetes: report from the Swedish National Diabetes Register. Diabetes Obes Metab 2016; 18 (10): 990-8. https://doi.org/10.1111/dom.12704

162. Gamble JM, Chibrikov E, Twells LK, eT AL.: Association of insulin dosage with mortality or major adverse cardiovascular events: a retrospective cohort study. Lancet Diabetes Endocrinol 2017; 5 (1): 43-52. https://doi.org/10.1016/S2213-8587(16)30316-3

163.JAnka HU, Ziegler AG, Standl E, Mehnert $\mathrm{H}$ : Daily insulin dose as a predictor of macrovascular disease in insulin treated non-insulin-dependent diabetics. Diabete Metab 1987; 13 (3 Pt 2): 359-64

164.MANSOOR N, VinkNes KJ, VEIERød MB, RETTERSTøL K: Effects of low-carbohydrate diets v. low-fat diets on body weight and cardiovascular risk factors: a meta-analysis of randomised controlled trials. $\mathrm{Br} \mathrm{J}$ Nutr 2016; 115 (3): 466-79 B. Veierød (a1) (a2) and Kjetil Retterstøl (a1) (a3). https://doi.org/10.1017/ S0007114515004699

165. Gershuni VM, Yan SL, Medici V: Nutritional Ketosis for Weight Management and Reversal of Metabolic Syndrome. Current Nutrition Reports 2018; 7 : 97-106. https://doi.org/10.1007/s13668-018-0235-0

166.Bhanpuri NH, Hallberg SJ, Williams PT, eT AL.: Cardiovascular disease risk factor responses to a type 2 diabetes care model including nutritional ketosis induced by sustained carbohydrate restriction at 1 year: an open label, non-randomized, controlled study. Cardiovasc Diabetol 2018; 17 (1): 56 https:// doi.org/10.1186/s12933-018-0698-8

167. Gershuni VM, YAN SL, Medici V: Nutritional Ketosis for Weight Management and Reversal of Metabolic Syndrome. Current Nutrition Reports 2018; 7 : 97-106. https://doi.org/10.1007/s13668-018-0235-0

168. Grandl G, STraub L, Rüdiger C, eT al.: Shortterm feeding of a ketogenic diet induces more severe hepatic insulin resistance than a obesogenic high-fat diet. J Physiol 2018; Epub ahead of print. doi: 10.1113/ JP275173. https://doi.org/10.1113/JP275173

169.Kosinski C, JornaYvaz FR: Effect of Ketogenic Diets on Cardiovascular Risk Factors: Evidence from Animal and Human Studies. Nutrients 2017; 9: 517 https://doi.org/10.3390/nu9050517

170. Mardinoglu A, Wu H, BJornson E, et Al.: An Integrated Understanding of the Rapid Metabolic Benefits of a Carbohydrate-Restricted Diet on Hepatic Steatosis in Humans. Cell Metab 2018; 27 (3): 55971.e5 https://doi.org/10.1016/j.cmet.2018.01.005

171.Brouns F: Overweight and diabetes prevention: is a low-carbohydrate-high-fat diet recommendable? Eur J Nutr 2018; 57 : 1301-12. https://doi.org/10.1007/ s00394-018-1636-y
172. Chin A: Copper Deficiency Anemia and Neutropenia Due to Ketogenic Diet. Pediatrics 2018; 141 (5) doi: 10.1542/peds.2017-3286

173.Ari C, Kovács Z, Murdun C, et Al.: Nutritional ketosis delays the onset of isoflurane induced anesthesia. BMC Anesthesiol 2018; 18 (1): 85 CrossRef MEDLINEPubMed Central

174.AвBASI J: Interest in the Ketogenic Diet Grows for Weight Loss and Type 2 Diabetes. JAMA 2018; 391 : 215-7 doi:10.1001/jama.2017.20639

175.Deutsche Gesellschaft für Ernährung (DGE): Kohlenhydrate, Ballaststoffe. (Angaben unter Referenzwerten). https://www.dge.de/ wissenschaft/referenzwerte/ kohlenhydrate-ballaststoffe/

176.https://bmcanesthesiol.biomedcentral.com/articles/10.1186/s12871-018-0554-0 Nutritional ketosis delays the onset of isoflurane induced anesthesia

177.Vargas S, Romance R, Petro JL, et al.: Efficacy of ketogenic diet on body composition during resistance training in trained men: a randomized controlled trial. J Int Soc Sports Nutr 2018; 15 (1): 31. doi $10.1186 /$ s12970-018-0236-9

178. Rodger S, Plews D, Laursen P et AL. (2017). Oral $\beta$-hydroxybutyrate salt fails to improve 4-minute cycling performance following submaximal exercise. J Sci Cycling 6: 26-31

179. O'Malley T, Myette-Cote E, Durrer C et al. (2017) Nutritional ketone salts increase fat oxidation but impair high-intensity exercise performance in healthy adult males. Appl Physiol Nutr Metabol 42: $1031-1035$

180.Stubbs BJ, Cox PJ, Evans RD et al. (2017) On the metabolism of exogenous ketones in humans. Front Physiol 8: 137

181.Paoli A, Rubini A, Volek JS et al. (2013) Beyond weight loss: a review of the therapeutic uses of verylow-carbohydrate (ketogenic) diets. Eur J Clin Nutr 67: 789-796

182. Gibson AA, Seimon RV, Lee CMY et al. (2015). Do ketogenic diets really suppress appetite? A systematic review and meta-analysis. Obes Rev 16: 64-76 35. Danaher J, Nyholm S, Earp BD (2018) The quantified relationship. Am J Bioeth 18: 3-19

183. Paton C, Hansen M, Fernandez-Lugue L et al. (2012) Self-tracking, social media and personal health records for patient empowered self-care. Contribution of the IMIA social media working group. Yearb Med Inform 7: 16-24

184. Gautschi M, Weisstanner C, Slotboom J eT AL. (2015) Highly efficient ketone body treatment in multiple acyl-CoA dehydrogenase deficiency-related leukodystrophy. Pediatr Res 77: 91-98

185.ECKERT, NADINE Kohlenhydrate und Lebenserwartung: Low Carb unter Verdacht Dtsch Arztebl 2018; 115(41): A-1816 / B-1528 / C-1514 
186. Sara B Seidelmann, Brian Claggett, Susan Cheng, Mir Henglin, Amil Shah, Lyn M StefFen, Aaron R Folsom, Eric B Rimm, Walter C Willett, ScotT D Solomon Dietary carbohydrate intake and mortality: a prospective cohort study and meta-analysis Lancet Public Health 2018; 3 (9): e419-28

187. Low Carb-Ernährung ist gefährlich und sollte gemieden werden Prof. Dr. Eckart Fleck Pressesprecher Deutsche Gesellschaft für Kardiologie - Herz- und Kreislaufforschung e.V. https://idw-online.de/en/ news701236

188. Associations of fats and carbohydrates with cardiovascular disease and mortality-PURE and simple? Stefan Lorkowski, Margrit Richter, Jakob Linseisen, Bernhard Watzl, on behalf of the German Nutrition
Society Thelancet Vol 391 391, ISSUE 10131, P16781679, APRIL 28, 2018 DOI: https://doi.org/10.1016/ S0140-6736(18)30800-6

189.U.S. News. U.S. News' 40 best diets overall. 03. Januar 2018. URL: https://health.usnews.com/wellness/ food/slideshows/bestdiets-overall Zugriff 21.02.18

190.U.S. News. Best fast weight-loss diets. URL: https:// health.usnews.com/best-diet/bestfast-weight-lossdiets Zugriff 21.02.18

191. WILDER RM (1921) The effects of ketonuria on the course of epilepsy. Bull Mayo Clin 2: 307

192.Dehghan M, Mente A, Zhang X, et Al. Associations of fats and carbohydrate intake with cardiovascular disease and mortality in 18 countries from five continents (PURE). Lancet 2017; 390: 2050-62. 